\title{
Why is the SKY BLUE? \\ On colour signs in Icelandic Sign Language
}

\author{
Rannveig Sverrisdóttir and \\ Kristín Lena Thorvaldsdóttir ${ }^{1}$
}

\section{ICELANDIC SIGN LANGUAGE ${ }^{2}$}

Icelandic Sign Language (ÍTM, Íslenskt táknmál) is the first language of approximately 300 Deaf signers in Iceland. ÍTM is an autonomous language that obtained legal status as the first language of Deaf people in Iceland in 2011. At the same time, Icelandic, ÍTMs surrounding language, obtained legal status as Iceland's official language. There is a Deaf Association in Iceland, established in 1960, that serves as a venue for social gatherings as well as being the headquarters for the fight for Deaf rights in Iceland.

Most of ÍTMs speakers live in or around the capital (Reykjavík) and therefore there is no geographical variation between speakers. No gender variation has been attested in ÍTM but there is significant lexical, morphological and syntactic variation between age groups (see Sigurbjörnsdóttir 2011, Thorvaldsdóttir 2011, Brynjólfsdóttir 2012 and Brynjólfsdóttir and Thorvaldsdóttir 2014).

In the years 1820 to 1867 Icelandic deaf children were sent to school in Denmark (Benidiktsson and Gíslason 1869:113-114). There are no reliable resources available on deaf people or sign language in Iceland before that time. The first school for the deaf in Iceland was established in 1867 by Reverend Páll Pálsson. Pálsson had been sent to a school for the deaf in Copenhagen since he lost his hearing at a young age. There he learned to sign, presumably he learned Danish Sign Language (DTS, Dansk tegnsprog). He then regained his hearing and returned to Iceland. Later he was asked by the Icelandic government to go back to Denmark to learn the basics in teaching deaf children. When he returned yet again from Denmark he established a school for the deaf at Prestbakki rectory. His goal was to teach the children the basics of Christianity and he did that through both 
writing and what was called "finger language" which was presumably the predecessor of ÍTM (Pálsson 1867, 1874a, 1874b; see also Thorvaldsson 2010). None of Pálsson's students studied in Denmark before they attended the school in Iceland and there was no Deaf Association in Iceland at that time.

It is therefore likely that influence from DTS, if any at that time, came from the language Pálsson used. Pálsson's successors also studied in Denmark and brought with them various techniques for teaching deaf children, e.g. Mouth-Hand system (Thorvaldsson 2010:46). Today there is no Deaf school in Iceland but many deaf children attend Hlíðaskóli, a mainstreaming school, with a sign language department.

Due to various language contact situations over time, ÍTMs relation to DTS can be seen quite clearly in a lexical comparison between ÍTM and DTS. According to Aldersson and McEntee-Atalianis (2008) there is a significant similarity between the two languages in some semantic categories, e.g. country signs, colour signs and kinship signs. Their inventory consisted of 270 signs, including 6 colour signs (blue, green, black, yellow, red and white), 12 kinship signs and an additional list of 30 country signs. They conclude that $37 \%$ of all the signs are different, $16 \%$ similar and $47 \%$ identical according to their analytic categories. No other research has been undertaken to investigate similarities between the two languages in other fields, e.g. on the syntax. When comparing the lexicon in the oldest DTS dictionary (DTS 1871) to contemporary ÍTM in the latest ÍTM dictionary (ÍTM 2012), for the purpose of the research described in this paper, there is a striking resemblance between the languages. It is therefore highly likely that this lexical relation can be traced back to the language used in the first school for the deaf in Iceland in 1867. It is also possible that the resemblance is due to other language contact situations over time, and in some cases the similarities between the languages could be due to iconicity.

In the sixties and seventies the Nordic Council of the Deaf (DNR, Døves Nordiske Råd) supervised a standardisation of signs in the Nordic sign languages; Icelandic Sign Language, Danish Sign Language, Swedish Sign Language (STS, Svensk teckenspråk), Norwegian Sign Language (NTS, Norsk tegnspråk) and Finnish Sign Language (SVK, Suomalainenviittomakieli). ${ }^{3}$ In that time research on sign languages was at its infancy and Deaf people had no knowledge of their sign languages being real languages with a grammatical structure and their own lexicon. Some of the results of this work were published in a dictionary in 1967, Handbook for Sign Language(s), which was heavily influenced by signs from DTS (DTS 1967). ${ }^{4}$ Iceland joined this collaboration at a later stage but ÍTMs lexicon 
was influenced by this standardisation. However, this influence was not only from DTS but also from the other Nordic sign languages. Due to various language contact situation, including but certainly not exclusively the standardisation, the other Nordic sign languages have been influenced by each other (Bergman and Engberg-Pedersen 2010).

Influence from DTS is also obvious at a later stage. Signs from DTS were printed in the second ÍTM dictionary (ÍTM 1987). In the foreword, a Deaf member of the committee that worked on collecting signs for the dictionary claims that some signs in the dictionary are signs that the DNR chose as Nordic signs during the standardisation. She also states that the Danish-Sign Dictionary (DTS 1979) was used to fill in the gaps, so to speak (Gudjónsdóttir 1987). This ÍTM dictionary (ÍTM 1987) was used by parents and teachers of deaf children, most of whom did not have any knowledge of ÍTM before it was published. It can therefore be argued that the dictionary has had considerable influence on the language the children acquired.

Research on ÍTM began when the Communication Centre for the Deaf and Hard of Hearing was established in 1991 and when Sign Linguistics became a subject at the University of Iceland in 2001, research increased. Nevertheless İTM is still, like many other sign languages, an understudied language and only a few aspects of ÍTM grammar have been examined (see e.g. Sverrisdóttir 2000 on simultaneous events in ÍTM, Thorvaldsdóttir 2008 on the use of space in ÍTM, Thorvaldsdóttir 2011 on plain verbs and agreement verbs in ÍTM, Brynjólfsdóttir 2012 on wh-questions in ÍTM and Gudmundsdóttir Beck 2013 on the meaning and origins of descriptive words in sign language). For a recent overview of the grammar of ÍTM, see Brynjólfsdóttir et al. (2012).

\section{Overview}

This study focuses on colour signs in Icelandic Sign Language. In the introduction we will first discuss Berlin and Kay's (1969) model on basic colour terms in spoken languages and its applicability to sign languages. Secondly, we will address the issue of language contact and standardisation since this study reveals a clear influence from other Nordic sign languages. In section 2 we will first discuss the methodology applied in this study followed by a description of all the basic colour terms that have signs in ÍTM. In each of the colour sign subsections we will give special attention to the colour signs etymology concerning language contact and standardisation. Before 
summarising section 2 we will briefly discuss how colour signs in ÍTM can be modified. In section 3 we will discuss the applicability of Berlin and Kay's (1969) model to ÍTM colour signs, considering revisions and criticism on their model from other scholars. We will discuss further the colour signs etymology since, for the newer colour signs, the present study reveals a clear influence from the Nordic sign languages, in particular DTS. In section 4 we will conclude.

\section{Introduction}

\subsection{Basic colour terms in spoken and sign languages}

In their well-known study on colour terms, Berlin and Kay (1969) claim that there are universal tendencies and implicational hierarchies in colour terms in spoken languages. From their inventory, any given language draws its eleven or fewer colour terms. These eleven colour terms are white, black, red, green, yellow, blue, brown, purple, pink, orange and grey. Berlin and Kay's (1969:2) model claims that there are strict limitations on which categories a language encodes, if it encodes fewer than eleven basic colour categories. Their implicational hierarchy can be seen in (1).

\section{(1) Berlin and Kay's (1969) implicational hierarchy}

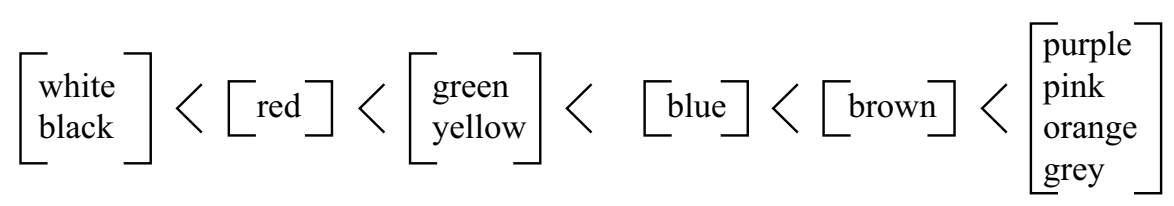

According to Berlin \& Kay, each basic colour term should exhibit the following characteristics (1969:6):

1) it should be monolexemic, the meaning should not be predictable from the meaning of its parts,

2) its signification cannot be included in that of any other colour term,

3) its application must not be restricted to a narrow class of objects,

4) it must be psychologically salient for informants.

Should there be any doubtful cases Berlin \& Kay (1969:6-7) give some subsidiary criteria. These criteria are the following: 
5) the doubtful form should have the same distributional potential as the previously established basic terms,

6) colour terms that are also the name of an object characteristically having that colour are suspect,

7) recent foreign loan words may be suspect,

8) in cases where lexemic status is difficult to assess, morphological complexity is given some weight as a secondary criterion.

In their reformulation of Berlin and Kay's model, Kay and McDaniel (1978) use fuzzy set theory to model the structure of individual colour categories. They analyse brown, purple, pink, orange and grey as derived from the other six colours, e.g. brown from black and yellow and purple from red and blue. Since the derived colour terms are not, according to Kay and McDaniel, fuzzily contained in the colours they are derived from, their signification is not included in that of any other colour term as Berlin and Kay's criterion 2) states (see further discussion in Kay and McDaniel 1978).

Not everyone agrees with Berlin and Kay's model. Wierzbicka (2008) criticises it and states that it is not correct to talk about language universals as not all languages do have the concept of colour and therefore do not have colour terms in the language. Wierzbicka argues that in Warlpiri, an Australian aboriginal language, there is no word for colour and speakers of the language do not think about colour terms when talking. Instead they describe things in terms of what they look like, like yukuri is "what the earth looks like after rain' — something an English speaking person would call green (2008:410-411).

Some scholars have discussed how to define basic colour terms in sign languages and whether Berlin and Kay's model is in fact universal. Woodward (1989) was the first to systematically investigate colour terms across sign languages. The sign languages he examined exhibit between two and nine basic colour terms. Woodward's conclusion is that colour signs in sign languages follow the same universal pattern found in spoken languages (1989:150).

Nyst (2007:91-97), on the other hand, claims that Berlin and Kay's model faces a methodological problem in the case of sign languages, even though she claims that Woodward (1989) might be right by saying that colour terms in sign languages follow a universal pattern. According to her there are five ways to form colour terms in sign languages; 1) derivation, 2) pointing, 3) mouthing, 4) initialisation and 5) then there are arbitrary colour signs. 
Colour terms made by pointing can be said to be derived and signs made by mouthing and initialisation are influence from spoken languages, therefore non-native. Nyst (2007:92) claims the following:

Strictly applying Berlin and Kay's criteria, only the arbitrary colour signs (type 5) should be considered basic colour terms, as all other types of colour signs are either derived (type 1 and 2) or non-native (type 3 and 4). Yet, arbitrary colour signs are rare in sign languages and tend to refer to colours low in the hierarchy, e.g. the signs PURPLE and BROWN in NGT.

Derived colour signs in sign languages are often also the name of an object characteristically having that colour and should, according to Nyst therefore be excluded by the subsidiary criteria in Berlin and Kay's model. Hollmann and Sutrop (2010:135) argue that Nyst has taken the original definition of basic colour terms too literally. They point out that the subsidiary criteria should only be applied in situations when the status of a term is not clear after analysing it with the help of the four primary criteria (2010:135). That is, derived and non-native colour signs are only excluded by the subsidiary criteria and arbitrary signs can be excluded by the primary criteria. Hollmann and Sutrop claim that Berlin and Kay's (1969) model holds for colours terms in Estonian Sign Language as they follow their universal hierarchy. They conclude that nine colour terms in Estonian Sign Language meet the primary criteria and are basic (2010:148-149).

Colour terms in ÍTM and the applicability of Berlin and Kay's (1969) model to colour terms in ÍTM will be discussed in section 3.1.

\subsection{Language contact and standardisation}

As in other languages, ÍTM's lexicon changes over time. Generational variation in ÍTM has been attested; lexical, morphological and syntactic (Sigurbjörnsdóttir 2011, Thorvaldsdóttir 2011, Brynjólfsdóttir 2012 and Brynjólfsdóttir and Thorvaldsdóttir 2014).

Some signs in ÍTM are known as the old signs and are or have only been used by older signers. An example of this are the two signs for Christmas tree where one is older than the other. The older sign refers to a handmade ornament made from wood that look like a pine (see figure 1a). The newer sign and the most commonly used today is a compound of the signs CHRISTMAS and TREE and the sign CHRISTMAS refers to the outlines of a pine (see figure 1b). 


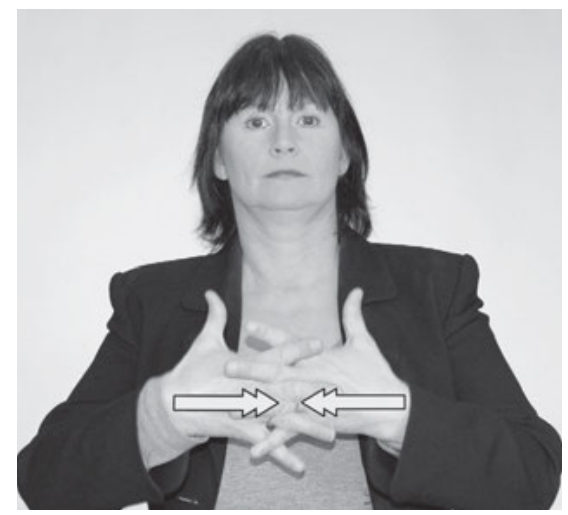

a) CHRISTMAS-TREE (old sign)

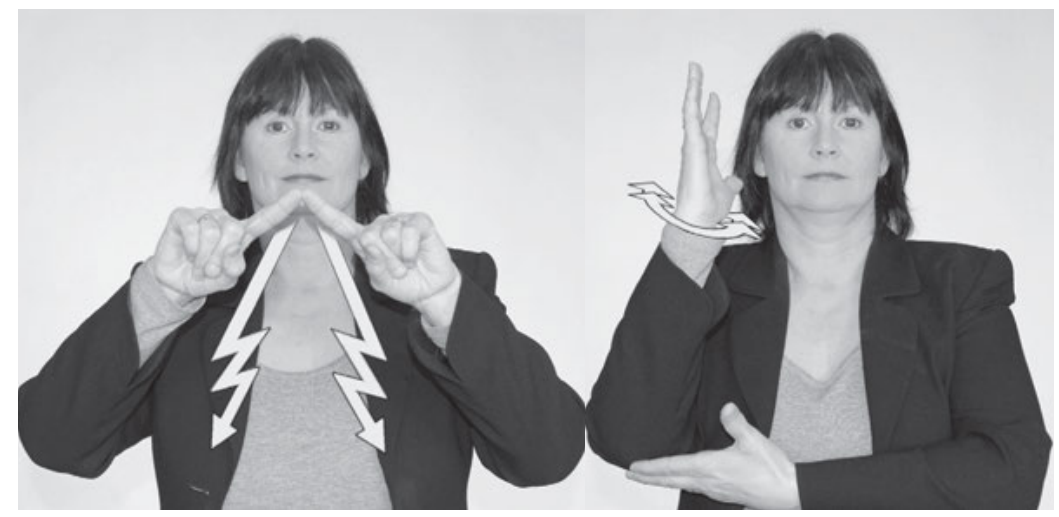

b) $\mathrm{CHRISTMAS}^{\wedge} \mathrm{TREE}$ (new sign)

Figure 1. Signs for Christmas tree in ÍTM

The terms old and new are also frequently used by signers when talking about colour signs in ÍTM and variation between older and younger signers is obvious when looking at colour signs. Most of the basic colour terms, in the terms of Berlin and Kay (1969), that have signs in ÍTM, have one new sign and one old sign. Black, red and yellow only have one sign each and have, according to our resources, never changed. Pink, grey and orange have more than two signs (see further discussion and figures in section 2.2). ${ }^{5}$

The language contact between ÍTM and DTS dates back to the nineteenth century and could have influenced the colour signs in ÍTM, both the old and the new. One explanation for the diversity of colour signs in ÍTM is the formerly mentioned standardisation of signs in the Nordic sign languages 
the DNR supervised in the sixties and seventies. Before the standardisation, ÍTM had its own colour signs (the old signs) that were for the most part quite different from the Nordic colour signs. Today, some of the colour signs in the Nordic sign languages are identical or similar and that can be due to the standardisation.

The first ÍTM dictionary was published in 1976 (ÍTM 1976) and only the old ÍTM colour signs were printed in that dictionary, nearly ten years after the standardisation dictionary was published (DTS 1967). But a second ÍTM dictionary published in 1987 (ÍTM 1987) both included the old and the new colour signs. In the foreword of the second ÍTM dictionary it said that the 1979 DTS dictionary was used to fill in the gaps (Gudjónsdóttir 1987). It is quite obvious that it didn't simply do that as the DTS signs were added to the previously existing lexicon for colour terms in ÍTM. In the latest ÍTM dictionary (ÍTM 2012) only the new colour signs appear. It is therefore reasonable to maintain that DTS had quite an influence on ÍTM colour signs.

\subsection{Summary}

In section 1 we have introduced Berlin and Kay's (1969) model on basic colour terms in spoken languages and how it applies to sign languages according to Woodward (1989), Nyst (2007) and Hollmann and Sutrop (2010). We then explained ÍTMs language contact situation and that the colour signs in ÍTM could have been influenced by the other Nordic sign languages, in particular DTS, pre, post and during the standardisation lead by the DNR. In the next section we will start with a methodology discussion and then account for all the basic colour terms that have signs in ÍTM and compare them with colour signs in the other Nordic sign languages.

\section{Colour terms in ÍTM}

\subsection{Methodology}

The aim of this study is to inventarise the colour signs in ÍTM, both old and new, to interpret our descriptive findings in the context of Berlin and Kay's model, and evaluate the role of language contact, in particular, the influence of DTS.

This study started with a questionnaire on kinship terms, colour terms and numerals from the iSLanDS Centre. We used the data elicited for that 
purpose in our present study but we also added both naturalistic and elicited data. The data used in this study is from 21 speakers of ÍTM, 10 women and 11 men, ranging from 28 to 84 years of age. Not all 21 speakers contributed to all of the following data.

The elicited data for the questionnaire is from two Deaf informants. They were set various tasks concerning colour terms and were also asked to produce the colour sign for 40 different colours after looking at different colour cards (colour naming task). We then asked two other Deaf informants to do the colour naming task for the same 40 colour cards.

We came across a recently videotaped interview with a Coda in her eighties, the only hearing person in her family, where she produced the colour signs she and her family used when she was a young girl. We then undertook interviews with three Deaf informants on colour signs, to find out how they distinguish between old and new colour signs and to consult them on the colour signs applications concerning Berlin and Kay's (1969) model. We also had 16 Deaf informants do a list task, that is, to produce all the colour signs they could, within 2 minutes, to check which colour terms were psychologically salient for the informants and what colour term they would name first. Some of them were also asked to point to a colour card when asked about a specific colour sign to check if informants thought of the same colour when using the old and the new sign for that colour. Eleven of those were asked by a Deaf interviewer whilst the other five met with Thorvaldsdóttir.

To evaluate the role of language contact, in particular the influence of DTS, we compared both the old and the new colour signs in ÍTM to colour signs in DTS in various dictionaries from both languages. We also used dictionaries from the other Nordic sign languages to be able to assess the extent of the standardisation and possible influence on ÍTM from Nordic sign languages other than DTS.

Comparing entries in dictionaries can be a questionable methodology due to many factors, e.g. it matters whether the Deaf community actually used the signs in the dictionaries, whether the editors of the dictionaries were hearing or Deaf, and what the purpose of the dictionaries was. All these factors have to be taken into account but this method can be justified by the fact that signs from other dictionaries influenced the ÍTM dictionary, as stated by the committee member in the foreword of the second ÍTM dictionary (ÍTM 1987). It is therefore interesting to compare dictionaries from all the Nordic sign languages.

We used the three published ÍTM dictionaries (ÍTM 1976, 1987, 2012) and five DTS dictionaries (DTS 1871, 1907, 1926, 1979, 2008). We also 
used the standardisation handbook that was influenced by DTS (DTS 1967). ${ }^{6}$ We then used online NTS, STS and SVK dictionaries (NTS 2011, STS 2013, SVK 2013). They only contain contemporary language and can therefore not tell us anything assertive about how old the signs are and if they were used both pre and post the standardisation. ${ }^{7}$

To compare the colour signs in ÍTM to other Nordic sign languages we used Aldersson and McEntee-Atalianis' (2008) analytic categories. They focused on three parameters; hand configuration, location and movement. They included the orientation of the hand in the hand configuration and excluded the mouthing since it had little or no weight in the comparison. According to them, a sign from one language is identical to a sign from the other language if all three parameters are the same. ${ }^{8}$ Similar signs share two parameters in common but differ in the third and different signs are signs where two or all parameters are different (2008:57-58).

\subsection{Basic colour terms}

Berlin and Kay (1969) claim that no language has more than eleven basic colour terms. ÍTM has signs that stand for each of these eleven colour terms and we claim that they are all basic (see further in section 3.1). In the following subsections we will inventarise the colour signs of ÍTM and describe their semantic relation to other signs in ÍTM or the real-world, e.g. the new sign for blue is identical to the sign for sky. In section 3.1 we will interpret our descriptive findings in the context of Berlin and Kay's model.

Most of the colour terms have both old and new signs in ÍTM. All the old ÍTM colour signs appear in the first ÍTM dictionary (ÍTM 1976). Both the old and the new ÍTM colour signs appear in the second ÍTM dictionary (ÍTM 1987) and only the new ÍTM colour signs appear in the latest ÍTM dictionary (ÍTM 2012). ${ }^{9}$

No data is available to confirm the origin of the old colour signs. We will therefore describe all the ÍTM colour signs, both old and new, but only speculate on the origin of the new signs and the signs that have never changed. ${ }^{10}$ To evaluate the role of language contact, in particular the influence of DTS, we will compare the ÍTM colour signs to colour signs in various DTS dictionaries using Aldersson and McEntee-Atalianis' (2008) analytic categories (see also section 2.1). We will also compare the ÍTM signs to signs in NTS, STS and SVK dictionaries to evaluate the influence of the Nordic sign language standardisation (see also section 1.2). 


\subsubsection{WHITE}

There are two signs for the colour white in ÍTM. The older sign is twohanded and that sign is identical to an old sign for snow in ÍTM, see figure 2. The semantic relation between those two older signs is that snow is white. The newer and more commonly used colour sign is a one-handed sign that is non-iconic and has no semantic relation to another sign in ÍTM, see figure 3 .

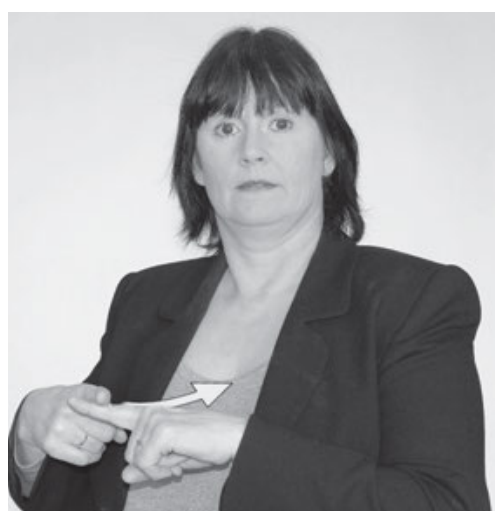

Figure 2. WHITE and SNOW in ÍTM (old signs)

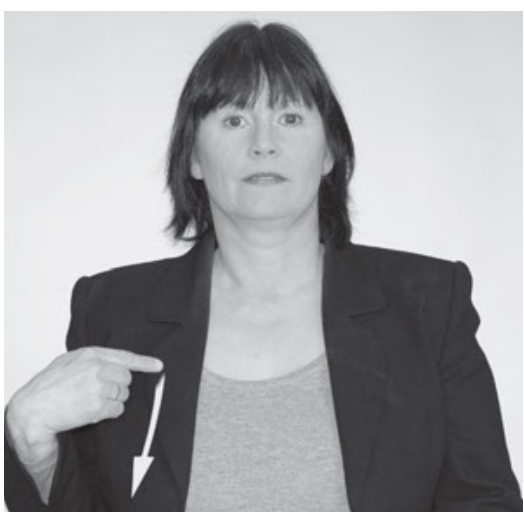

Figure 3. WHITE in ÍTM (new sign)

The DTS dictionaries show that the sign WHITE in DTS has stayed the same, at least since 1871 (DTS 1871, 1907, 1926, 1979, 2008). According to Aldersson and McEntee-Atalianis' (2008) analysis, the sign WHITE in DTS is different from the new sign WHITE in ÍTM, see figure 4 (DTS 2008).

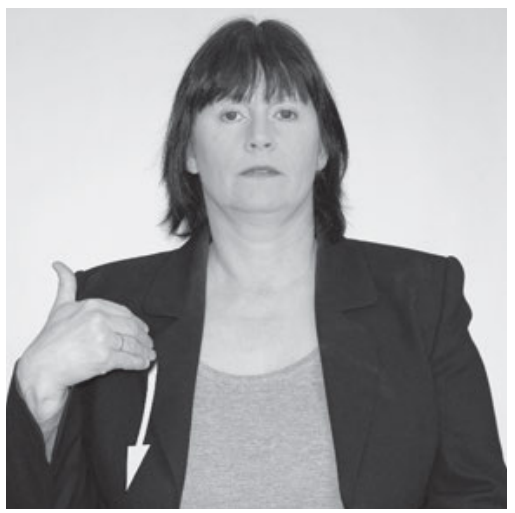

Figure 4. WHITE in DTS ${ }^{11}$ 
The origin of the new sign WHITE in ÍTM is unknown but it may have originated in the making of the second ÍTM dictionary (ÍTM 1987). It first appears in that dictionary, the dictionary that is claimed to have been influenced by DTS. The old sign is also in that dictionary but it does not appear in the latest dictionary (ÍTM 2012) and is only used by a few old speakers of ÍTM today. In the 1907 DTS dictionary it states that the DTS sign refers to a white collar or the chalk that a teacher would dust of his/ her clothes (DTS 1907:16). The new ÍTM sign's place of articulation is the same as in the DTS sign but the other parameters are different. Some signers use a repeated movement but others use a single movement. The former is the same movement as in the sign WHITE in DTS and makes the signs similar according to Aldersson and McEntee-Atalianis' (2008:63) analysis. The ÍTM sign could have been borrowed from DTS and then changed phonologically but nevertheless it is not a clear example of a borrowing from DTS.

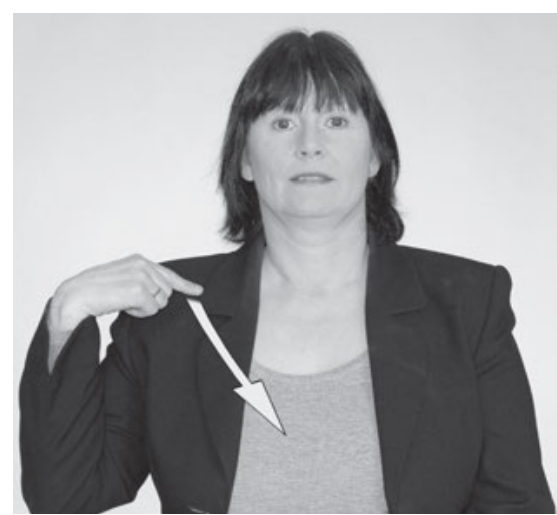

Figure 5. WHITE in STS and $\mathrm{SVK}^{12}$

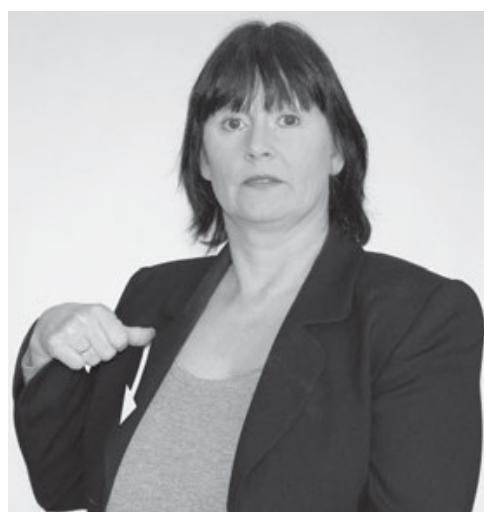

Figure 6. WHITE in $\mathrm{NTS}^{13}$

The new sign WHITE in ÍTM is similar to the sign WHITE (or one of the signs for white) in NTS, STS and SVK (NTS 2011, STS 2013, SVK 2013), see figures 5 and 6.

Since ÍTM had an old sign for white before the standardisation it is likely that the new ÍTM sign for white was borrowed from any of the Nordic sign languages and then changed phonologically. No documentation is available to confirm which language influenced another during the standardisation. 


\subsection{2. $B L A C K$}

There is only one sign for the colour black in ÍTM and no other sign has been used for that colour in ÍTM. The sign BLACK in ÍTM is a one-handed sign that is semantically and phonologically related to the signs NIGHT and DARK in ÍTM, see figures 7-9.

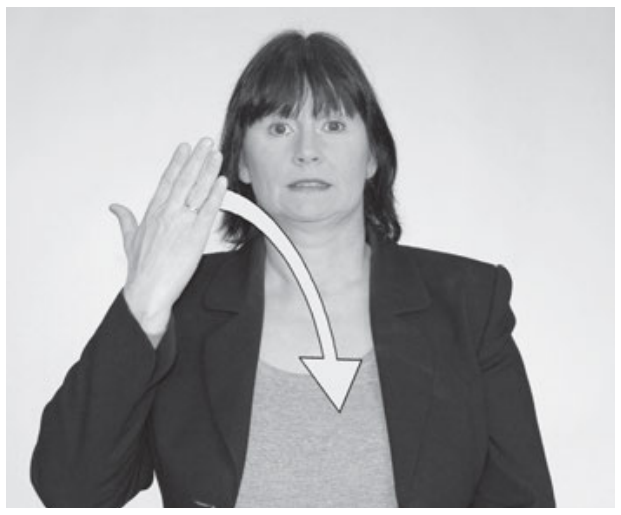

Figure 7. BLACK in ÍTM

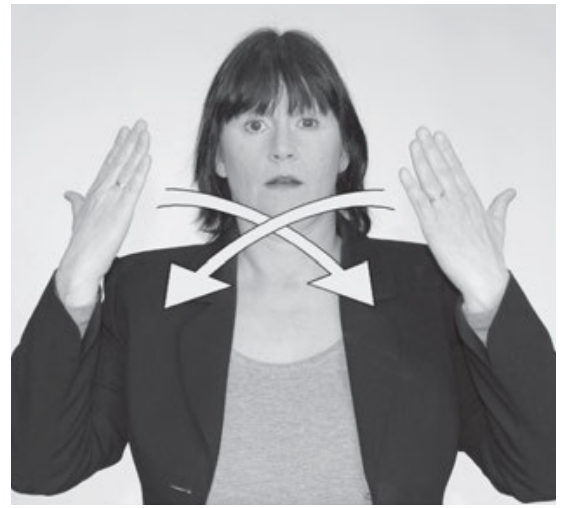

Figure 8. NIGHT in ÍTM

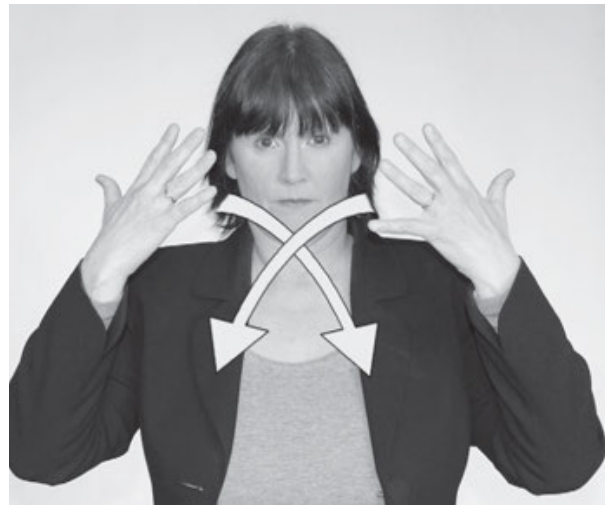

Figure 9. DARK in ÍTM

Those three signs are all articulated in a very similar way. NIGHT and BLACK are the same except NIGHT is a two-handed sign. DARK is a two-handed sign as well but with a slightly different handshape (5 instead of B). Informants say that the colour sign is derived from either of the other two signs. 
The contemporary signs DARK and EVENING in DTS and DARK and NIGHT in NTS and STS are identical to the sign NIGHT in ÍTM (DTS 2008, NTS 2011, STS 2013). The sign for BLACK in ÍTM is identical to the sign BLACK in DTS in all the DTS dictionaries except for the latest one (DTS 1871, 1907, 1926, 1979, 2008). There are three signs for the colour black exhibited in the 1979 DTS dictionary (DTS 1979), one of those is identical to the sign BLACK in ÍTM, the others are different. ${ }^{14}$ The identical sign is not commonly used in contemporary DTS and is not in the latest DTS dictionary (DTS 2008) ${ }^{15}$ but since the origins of the DTS sign can be traced all the way back to 1871 it is possible that Reverend Pálsson brought this sign with him from Denmark. The ÍTM sign is also identical to the sign BLACK in contemporary NTS and STS, but different from the SVK sign (NTS 2011, STS 2013, SVK 2013). Another possible explanation for this similarity is that the iconic and semantic relation between darkness, the night and the colour black in the Nordic sign languages, ${ }^{16}$ which could easily have originated in each language independent of the other.

\subsubsection{RED}

There is only one sign for the colour red in ÍTM and no other sign has been used for that colour in ÍTM. The sign RED in ÍTM is a one-handed sign, see figure 10. The signs place of articulation is just below the lower lip and the sign is semantically related to the sign MOUTH, see figure 11 . There is an iconic relation between the sign RED and the colour of the lips.

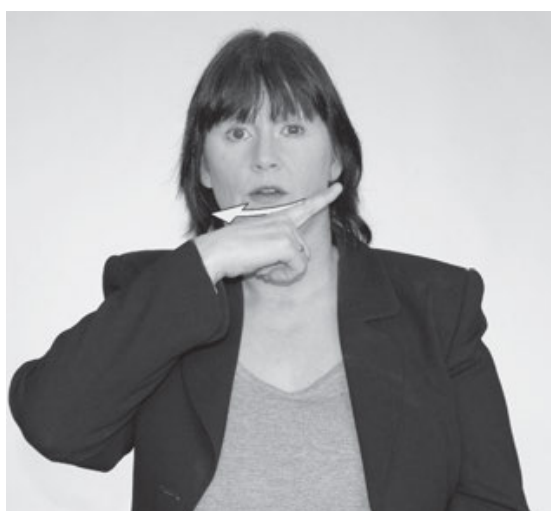

Figure 10. RED in ÍTM

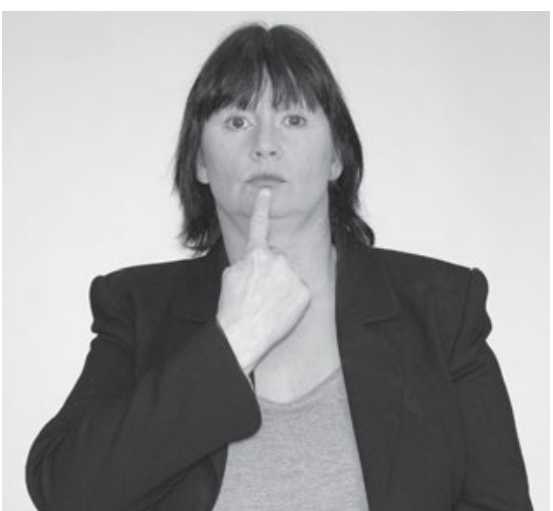

Figure 11. MOUTH in ÍTM 
The sign RED in DTS and NTS is similar, almost identical, to the sign RED in ÍTM, the movement is slightly different, see figure $12 .{ }^{17}$ In the ÍTM sign the hand moves from its contralateral side to its ipsilateral side, in the DTS and NTS signs the hand moves the other way around, it moves from its ipsilateral side to its contralateral side (see e.g. DTS 2008 and NTS 2011). According to the dictionaries, the DTS sign RED has stayed the same since 1871 (DTS 1871, 1907, 1926, 1979, 2008).

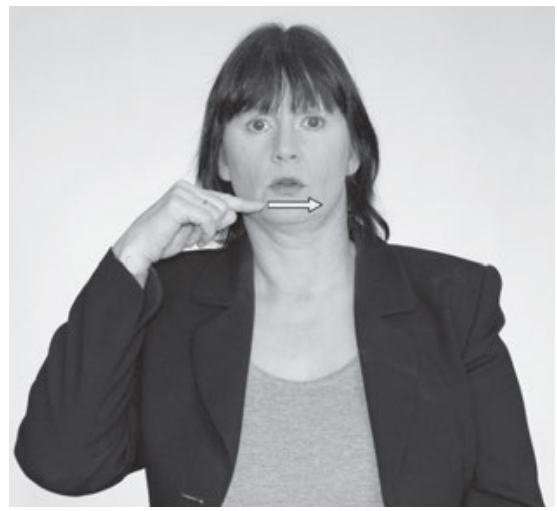

Figure 12. RED in DTS and NTS

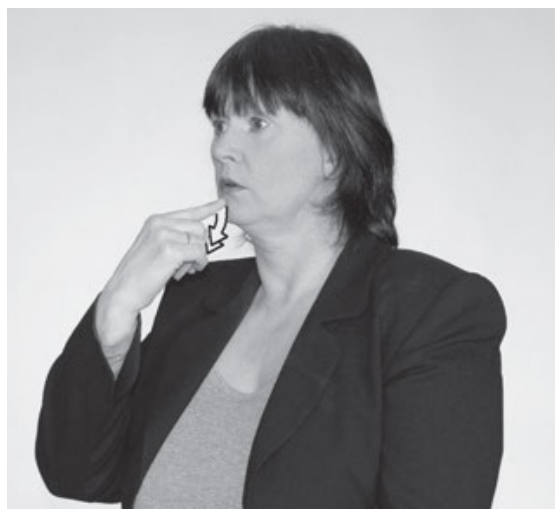

Figure 13. RED in STS

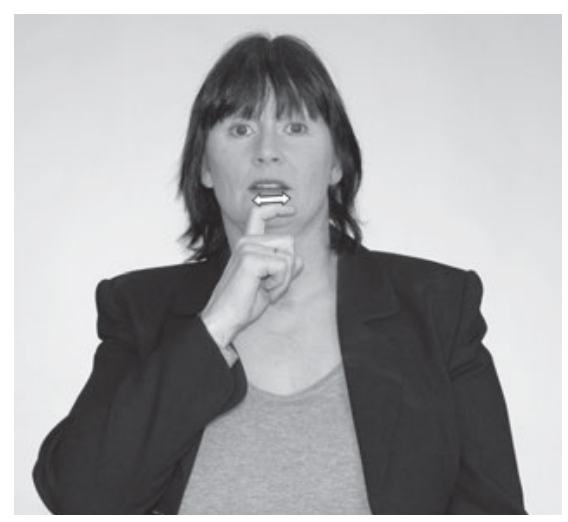

Figure 14. RED in SVK

The signs for red in many other sign languages, e.g. STS, SVK, ASL and BSL, have the same initial place of articulation and the same or similar initial handshape as the ÍTM sign, but different orientation and movement depending on the language (STS 2013, SVK 2013, ASL 2008, BSL 2011), see figures 13 and 14 for the STS and SVK signs. 
Even though the ÍTM sign could have been borrowed from DTS in late nineteenth century or from either DTS or NTS during other contact situations though time it is far more likely that the similarity is an artefact of iconicity since the signs for red in other sign languages seem to have the same semantic relation to the colour of the lips as the ITM sign.

\subsubsection{GREEN}

There are two signs for the colour green in ÍTM. The older sign is a onehanded sign with a circling movement, see figure 15 . The new sign GREEN is a two-handed sign with one hand active, see figure 16.

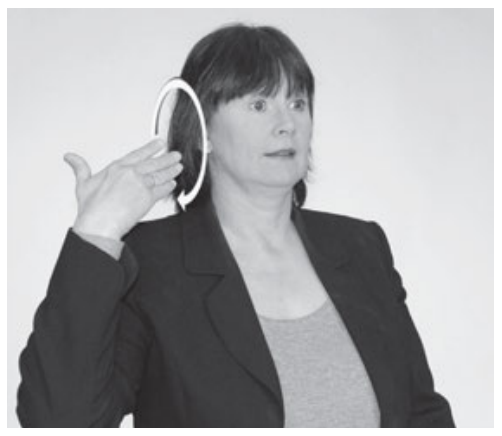

Figure 15. GREEN in ÍTM (old sign)

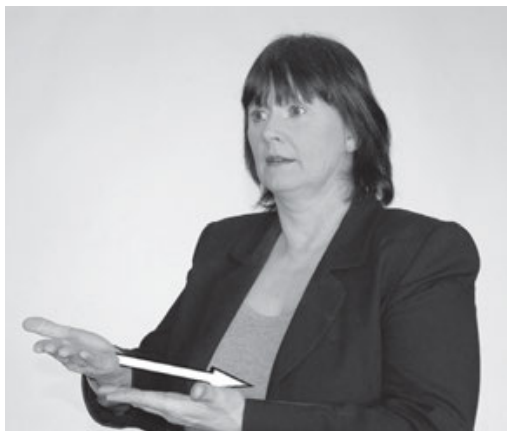

Figure 16. GREEN in ÍTM (new sign)

As for the old sign, informants do not recall any semantic relation to another sign or an iconic relation to the real-world. The new sign is iconic in that way that it literally means 'to cut grass' and is derived from how grass was cut with a scythe. The present sign TO-CUT-GRASS is similar to the new sign for green, see figure 17. The semantic relation lies in the colour of the grass that is typically green.

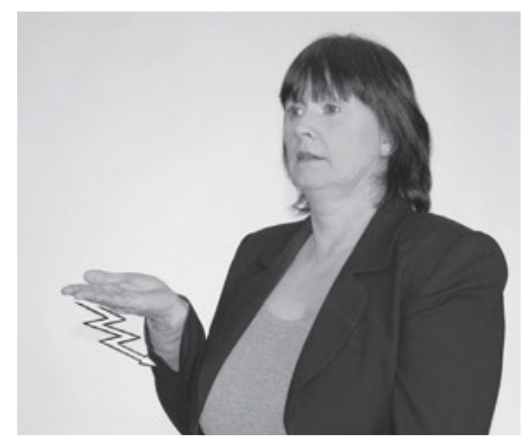

Figure 17. TO-CUT-GRASS in ÍTM 
Both the old and the new sign are used in contemporary ÍTM but the old sign is mostly used by older or middle aged signers whereas the new sign is used by younger generations and middle aged signers.

There are three signs for the colour green in DTS, see figure 18. The sign in $18 \mathrm{c}$ is the most commonly used in contemporary DTS but first appears in a dictionary in 1979 (DTS 1979, 2008). ${ }^{18}$ That sign is different from the new ÍTM sign and has no obvious relation to it. ${ }^{19}$ The new ÍTM sign is different from the sign in $18 \mathrm{a}$ but similar to the sign in $18 \mathrm{~b} .{ }^{20}$ One of the signs for green in STS and SVK are identical to the new ÍTM sign. The other STS and SVK signs and the NTS sign are different from the new ÍTM sign (NTS 2011, STS 2013, SVK 2013).

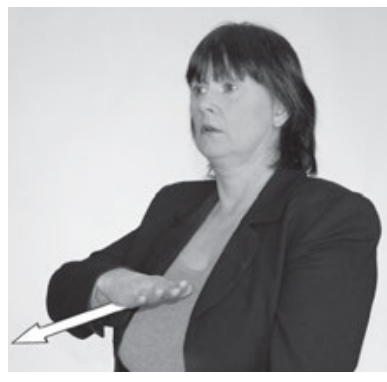

(a)

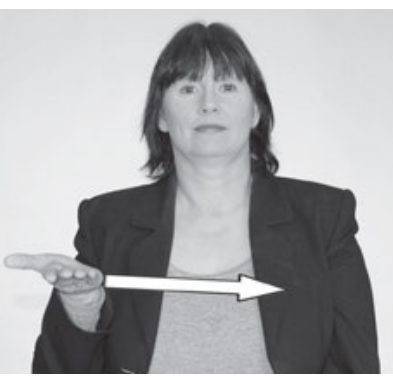

(b)

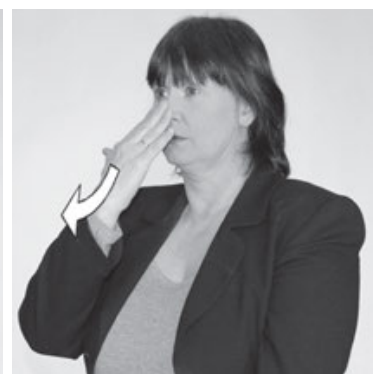

(c)

Figure 18. GREEN in DTS

The sign in figure 18a is the only sign for green in the three oldest DTS dictionaries (DTS 1871, 1907, 1926). A change in palm orientation and movement of the sign GREEN in DTS, as can be seen in the signs in $18 \mathrm{a}$ and $18 \mathrm{~b}$, occurred sometime mid-twentieth century. The sign in $18 \mathrm{~b}$ appears in the Handbook for Sign Language(s) (DTS 1967) and in the Danish-Sign Dictionary (DTS 1979). This change in the DTS sign could be a result of the standardisation and a possible loan from STS or SVK. The new ÍTM sign first appears in the second ÍTM dictionary (ÍTM 1987) and could therefore have entered ÍTM during the standardisation as a loan from STS or SVK. It could also have been borrowed from DTS after DTS borrowed it from another Nordic sign language during the standardisation. It is nevertheless noteworthy to mention that informants say that the new sign GREEN in ÍTM is derived from the act of cutting grass and therefore originated in ÍTM. 


\subsubsection{YELLOW}

The sign YELLOW in ÍTM is a two-handed sign with one hand active, see figure 19. Informants say that the sign YELLOW is derived from the sign CHEESE because the articulation of the sign refers to cutting cheese, see figure 20.

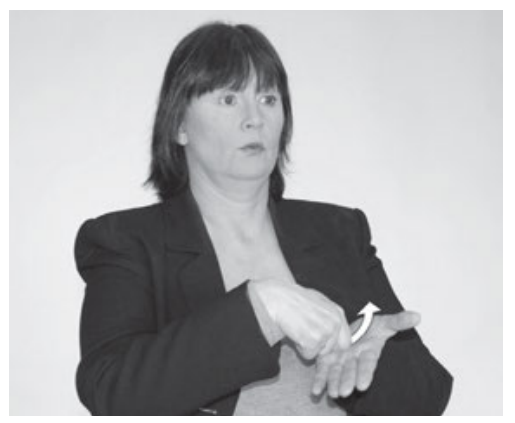

Figure 19. YELLOW in ÍTM ${ }^{21}$

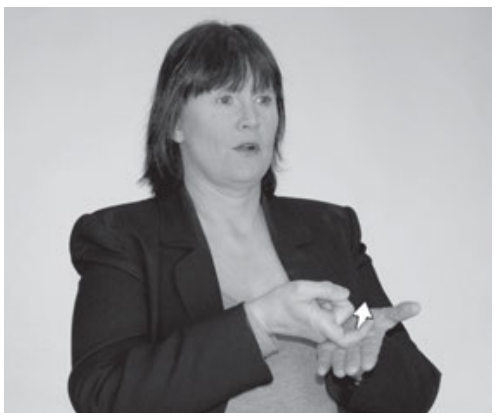

Figure 20. CHEESE in ÍTM

The signs YELLOW and CHEESE have the same movement, the same handshapes and the same location but different orientation. The semantic relation lies in the fact that cheese is typically yellow.

There is no older sign for yellow in ÍTM and the present sign YELLOW was therefore a part of the ÍTM lexicon before the standardisation of Nordic signs and the making of the second ÍTM dictionary (ÍTM 1987). It is then noteworthy to mention that the sign CHEESE in DTS is similar to the sign CHEESE in ÍTM (DTS 2008). On the other hand the signs for yellow in all the DTS dictionaries are different from the sign YELLOW in ITM. ${ }^{22}$ The DTS signs are said to be related to the act of squeezing a lemon (DTS 1907, 1926, 1967). ${ }^{23}$ The signs for yellow in NTS, STS and SVK are also different from the ÍTM sign (NTS 2011, STS 2013, SVK 2013).

Due to the similarity found in the signs for cheese in ITM and DTS the sign CHEESE in ÍTM could have been borrowed from DTS prior to the seventies, possibly in the nineteenth century. But the dissimilarity between the signs for yellow in ÍTM and the other Nordic sign languages indicates that the sign YELLOW originated in the productive lexicon of ÍTM itself. Since there is a semantic relation between the signs YELLOW and CHEESE in ÍTM, unlike DTS, the sign CHEESE could be an artefact of iconicity in ÍTM itself and the sign YELLOW derived from that sign due to the semantic relation to the colour of the cheese. 


\subsubsection{BLUE}

There are two signs for the colour blue in ÍTM, one old and one new, see figures 21 and 22 . The new sign is far more frequently used, only older signers use the old sign. Both signs are one-handed. The old signs place of articulation is around the eyes, see figure 21 . The new signs place of articulation is in neutral space, see figure 22.

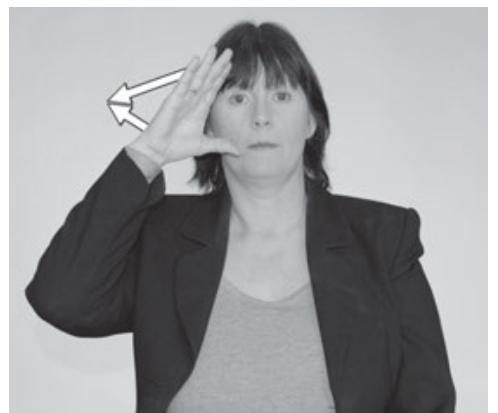

Figure 21. BLUE in ÍTM (old sign) $)^{24}$

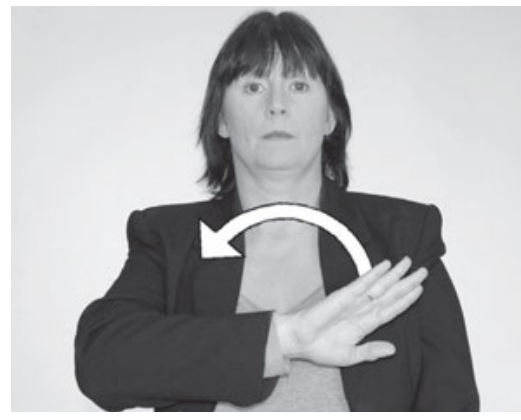

Figure 22. BLUE in ÍTM (new sign)

There is an iconic relation between the old sign and the colour of the eyes and our informants say that the semantic relation lies with the stereotype of NorthernEuropeans commonly being blond and blue eyed. The same could also be true for STS and SVK as the initial place of articulation in the signs for blue in those languages is also around the eyes (STS 2013, SVK 2013), see figure 23.

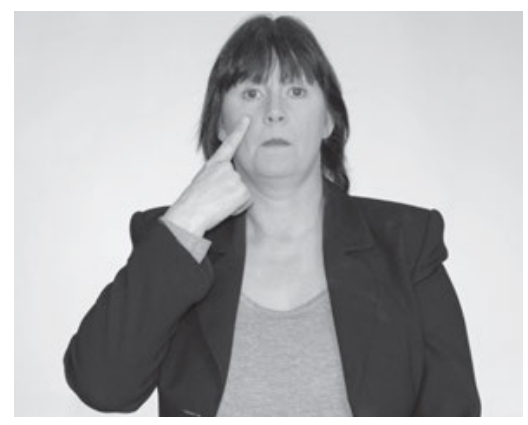

Figure 23. BLUE in STS and SVK

ÍTM has an old and a new sign for sky, see figures 24 and $25 .{ }^{25}$ Informants say that the new sign for blue is derived from the either of those signs. According to Aldersson and McEntee-Atalianis' (2008) analytic categories the old sign for sky is similar to the new sign for blue and the new signs for sky and blue are identical. The semantic relation lies in the fact that the sky is typically blue. 
There are two signs for the colour blue in DTS and one of them is found in all the DTS dictionaries except the latest one (DTS 1871, 1907, 1926, 1979). That sign and the sign SKY in DTS are identical to the new signs for sky and blue in ÍTM (see figure 22 and 25). The other DTS sign for blue is different from the new ÍTM sign but it is more commonly used in contemporary DTS (DTS 2008). ${ }^{26}$

There are also two signs for blue in NTS where one is identical to the new ÍTM sign for blue, the other is different. The sign for sky in NTS is similar to the old ÍTM sign for sky.

The fact that ITM had old signs for blue and sky before the standardisation of Nordic signs and the making of the second ÍTM dictionary (ÍTM 1987) could indicate that the new ITM signs were borrowed from DTS during or after the standardisation. It is also possible that the sign for blue was borrowed from NTS during the standardisation. The fact that ÍTM had an old sign for sky, similar to the DTS and NTS signs for blue could have made the borrowing semantically and phonologically easier. But the fact that there is an iconic and semantic relation between the signs for sky and blue in all the three languages, the signs for blue could easily have originated in each language independent of the other.

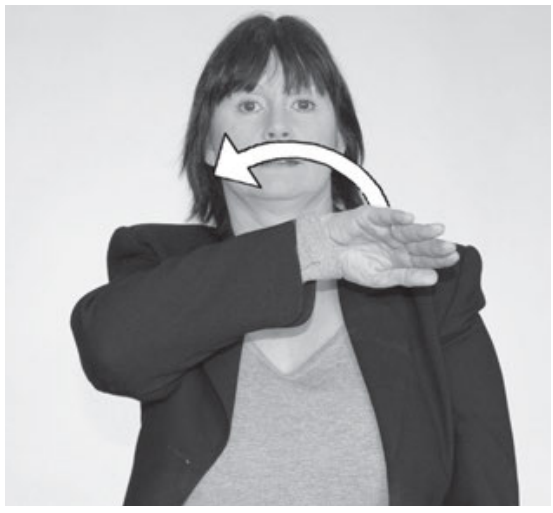

Figure 24. SKY in ÍTM (old sign)

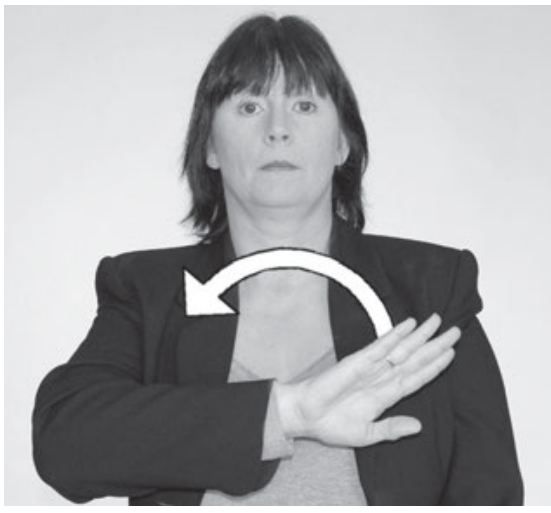

Figure 25. SKY in ÍTM (new sign)

\subsubsection{BROWN}

There are two signs for the colour brown in ÍTM. The new sign is more commonly used but the older one is used by older and some middle aged signers. Both are two-handed signs with an A-handshape on the dominant hand but the handshape of the non-dominant hand is different in the 
two signs. The old sign is identical to the sign COFFEE in ÍTM (see figure 26) whereas the new sign is identical to the sign for COCOA (see figure 27).

Both coffee and cocoa are typically brown, and there lies the semantic relation. Informants say that both signs for brown and the sign COCOA are derived from the sign COFFEE.

There are also two signs for the colour brown in DTS and they are identical to the two signs in ÍTM. The sign that is identical to the sign in figure 26 is found in dictionaries from 1871, 1926 and the latest one (DTS $1871,1926,2008)$. The other sign is found in the 1979 dictionary and in the Handbook for Sign Language(s) (DTS 1967, 1979), see figure 27. The signs for coffee and brown in NTS are identical to the old ÍTM sign for brown in figure 26 and the signs for cocoa are similar in NTS and ÍTM (NTS 2011), see figures 27 and 28. The signs for brown in STS and SVK are different from the ÍTM sign (STS 2013, SVK 2013).

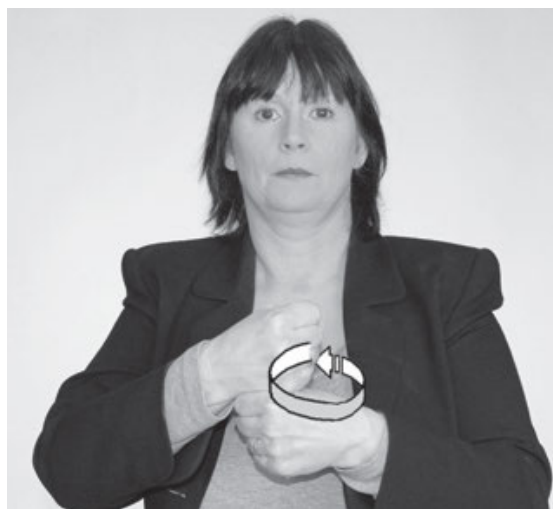

Figure 26. BROWN (old sign) and COFFEE in ÍTM

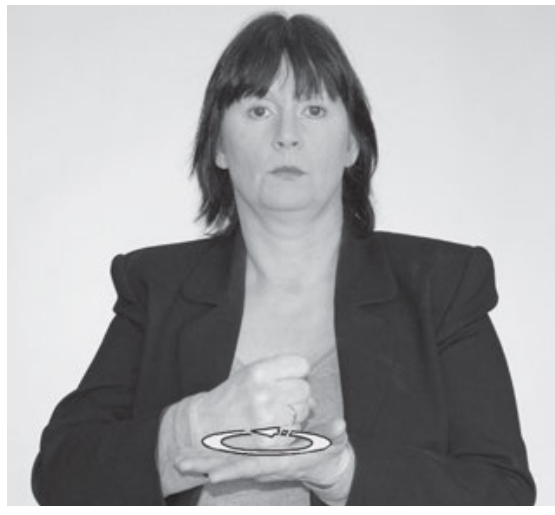

Figure 27. BROWN (new sign) and COCOA in ÍTM

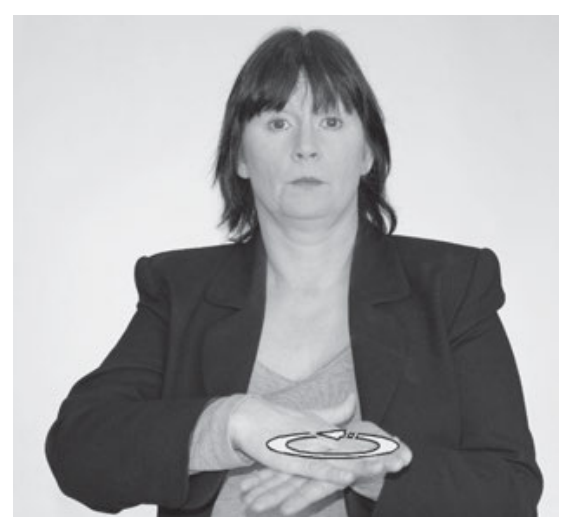

Figure 28. COCOA in NTS 
It is unlikely that the old ÍTM sign (that can also mean coffee) was borrowed from either DTS or NTS since the sign for coffee in many other sign languages is identical to the ÍTM sign, e.g. in STS, SVK and ASL (STS 2013, SVK 2013, ASL 2008). The new sign for brown (that can also mean cocoa) is on the other hand likely to have been borrowed from DTS during or after the standardisation. The reason for the DTS sign changing is unknown but the NTS sign for cocoa could have had an influence on the Nordic sign chosen for the standardisation handbook (DTS 1967), and therefore influenced ÍTM and DTS.

\subsubsection{PURPLE}

The colour term purple in ÍTM has two signs, both one-handed, see figures 29 and 30. The place of articulation in both signs is around the eyes and informants say that there is a semantic relation between the colour signs and a black-eye (or possibly periorbital circles). The iconic relation is that black-eyes are commonly purple, even though they can surely take on other colours, like the English term implies. One informant says that there is also a semantic and phonological relation between the old signs for purple and blue, see figures 21 and 29. The old sign is only used by a few older signers.

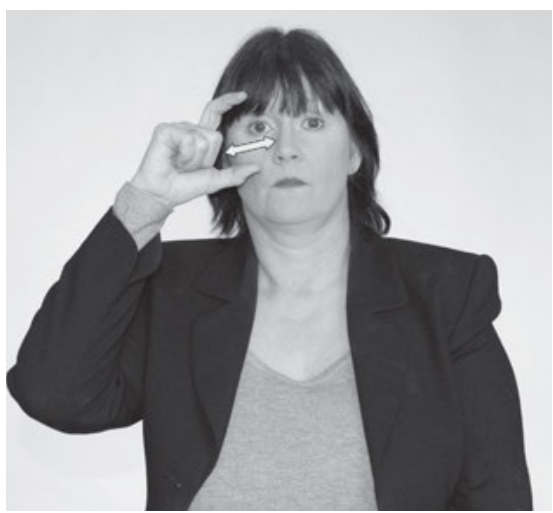

Figure 29. PURPLE in ÍTM (old sign)

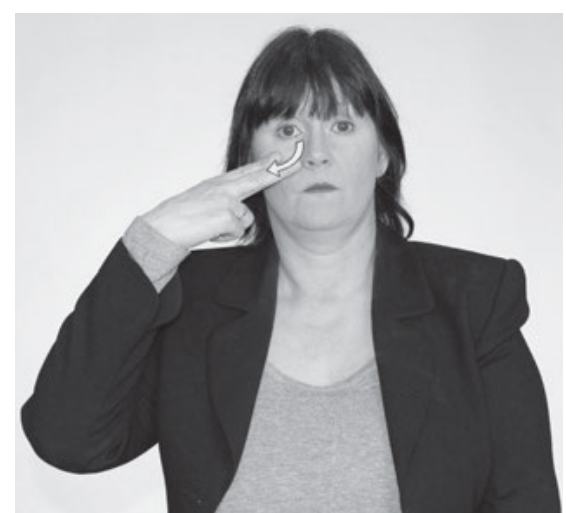

Figure 30. PURPLE in ÍTM (new sign)

The sign for purple in the standardisation handbook (DTS 1967) is a compound of the signs for blue and red and is different from the current sign for purple in all the Nordic sign languages. Nevertheless the current signs for purple in ÍTM, DTS, NTS and SVK (ÍTM 2012, DTS 2008, NTS 2011, SVK 2013) are identical and the sign could therefore be a neologism made by the 
DNR during the standardisation but after the handbook was published. The sign for purple in STS is on the other hand different (STS 2013).

\subsubsection{PINK}

There are three signs for the colour pink in ÍTM, one new and two older, all one-handed signs, see figures 31 and 32. The place of articulation of the older signs (figure 31 ) is the lower lip or just below the lower lip and like the sign RED they are semantically related to the sign MOUTH and they also refer to the colour of the lips, see figures 10 and 11 . These signs are rarely used for the colour pink in ÍTM today. ${ }^{27}$ The new sign (figure 32) is articulated on the cheek and the semantic relation is that the cheeks become pink when blushing.

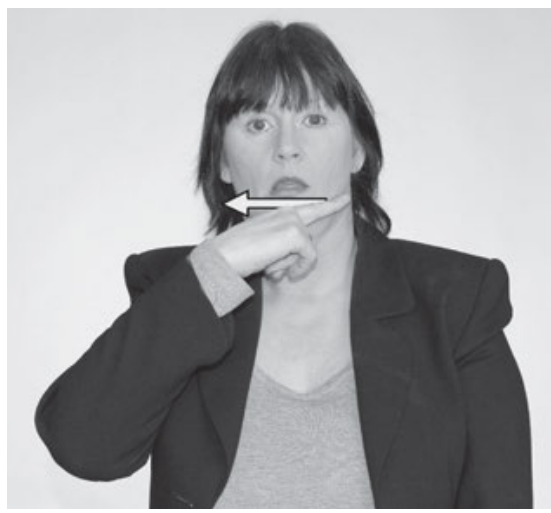

$\left(\right.$ a) ${ }^{28}$

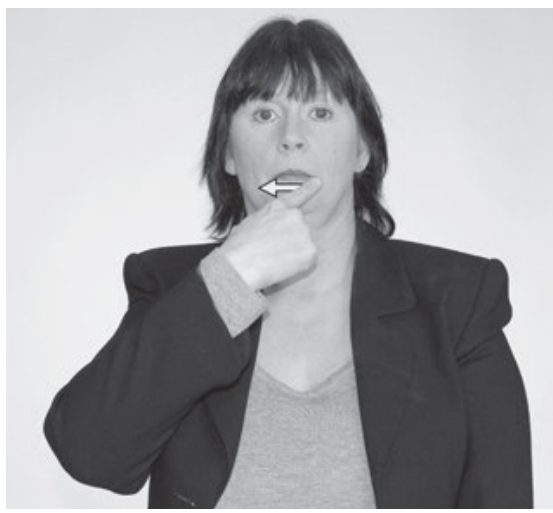

(b)

Figure 31. PINK in ÍTM (old signs)

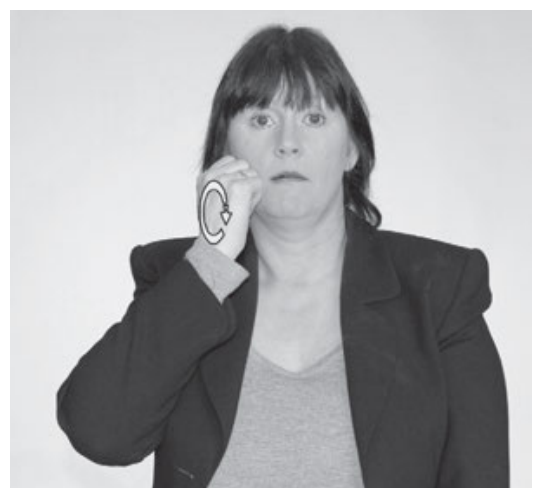

Figure 32. PINK in ÍTM (new sign) 
The new sign is identical to the sign PINK in DTS, NTS ${ }^{29}$ and SVK and seems similar to the sign PINK in STS, but according to Aldersson and McEnteeAtalianis' (2008) analytic categories they are different, see figure 33 (DTS $1979^{30}$, 2008, NTS 2011, STS 2013, SVK 2013).

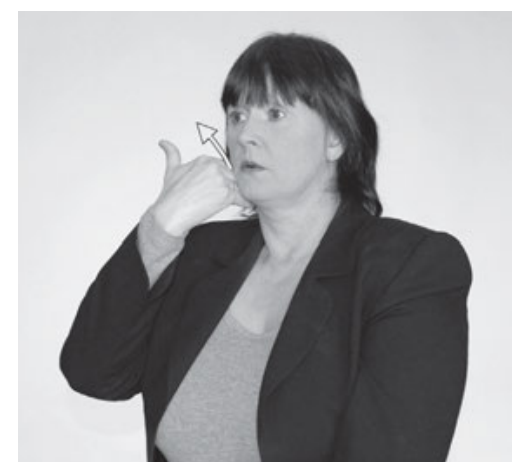

Figure 33. PINK in STS

There is no sign for pink in the standardisation handbook (DTS 1967) but since the current signs for pink in all the Nordic sign languages are identical or similar the sign could be, like the sign PURPLE, a neologism made by the DNR during the standardisation but after the handbook was published.

\subsubsection{ORANGE}

There are three signs for the colour orange in ÍTM. They are all one-handed and are articulated near the lower face, see figures 34-36.

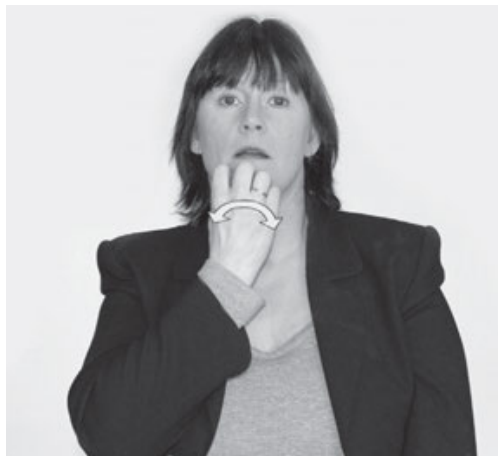

Figure 34. ORANGE in ÍTM (old sign)

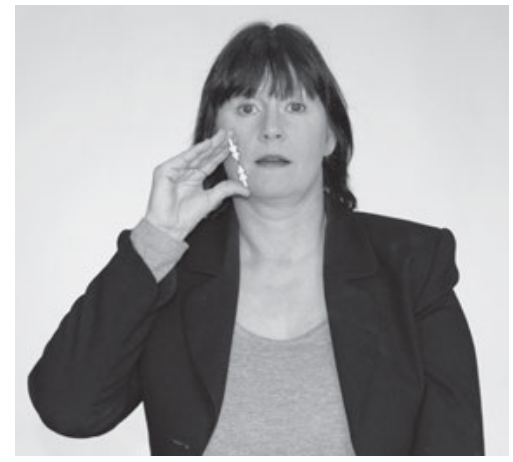

Figure 35. ORANGE in ÍTM (old/new sign) 


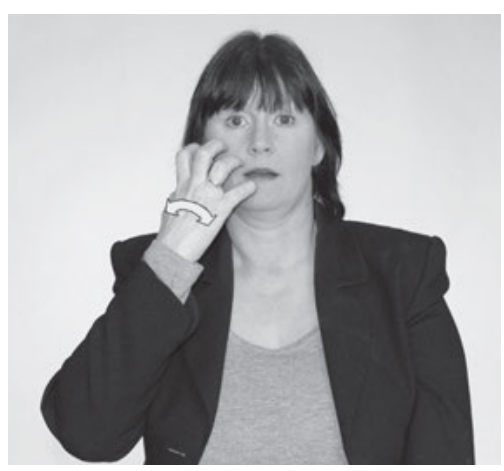

Figure 36. ORANGE in ÍTM (new sign)

The sign in 34 is the oldest and it appears in the first two ÍTM dictionaries but not in the latest ÍTM dictionary (ÍTM 1976, 1987). This sign was both used to refer to the fruit orange and the colour of the fruit. Most signers that use it, use it with a different place of articulation (on the cheek instead of the chin), it is rarely used the way it appears in the dictionaries.

The sign in 35 only appears in the second ÍTM dictionary (ÍTM 1987) and is considered younger than the sign in figure 34 but is only used by a few middle aged signers today. It cannot refer to the fruit but it can refer to the colour and a specific orange coloured soda drink. This sign is similar to the DTS colour sign ORANGE (DTS 1979, 2008), the place of articulation differs, see figure 37 .

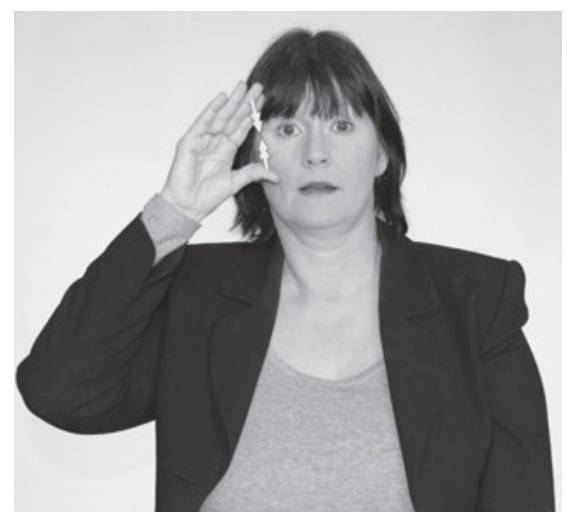

Figure 37. ORANGE in DTS

The sign in figure 36 is the youngest of the three. It first appears in the latest dictionary (ÍTM 2012) but it is considered much older than that. This sign can refer to both the fruit and the colour, the same as the old sign in 
figure 34. This sign is different from the signs for orange in all the Nordic sign languages (DTS 1979, 2008, NTS 2011, STS 2013, SVK 2013) and cannot have been borrowed.

The semantic relation between the fruit and the colour, in both the new sign in 36 and the old sign in figure 34, lies in the fact that oranges are orange. Their origin is most likely an artefact of iconicity. The semantic relation between the fruit and the sign in 35 on the other hand cannot be found in ÍTM. It can be found in DTS since the DTS sign can both refer to the fruit and the colour. ${ }^{31}$ The ÍTM sign in figure 35 is therefore a clear example of a borrowing from DTS. Interestingly, today all the ÍTM signs are articulated on or near the cheek, the oldest signs place of articulation has changed from the chin to the cheek and the sign borrowed from DTS changed its place of articulation from the eyes to the cheek.

\subsubsection{GREY}

There are three signs for the colour grey in ÍTM, all two-handed, see figures 38-40. Their place of articulation is similar, that is the non-dominant hand (figures 39 and 40) and the arm of the non-dominant hand (figure 38). According to our informants the signs for grey in ÍTM have no semantic relation with objects or body parts.

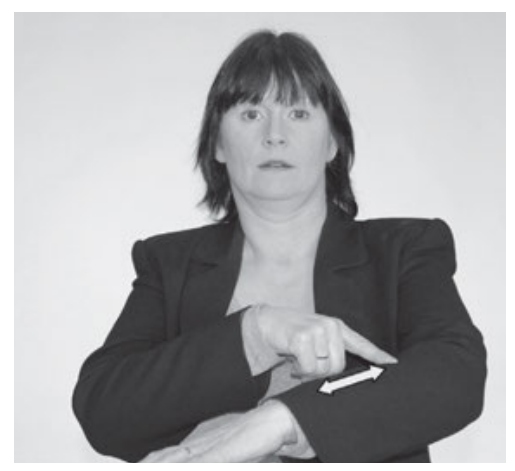

Figure 38. GREY in ÍTM (old sign) $)^{32}$

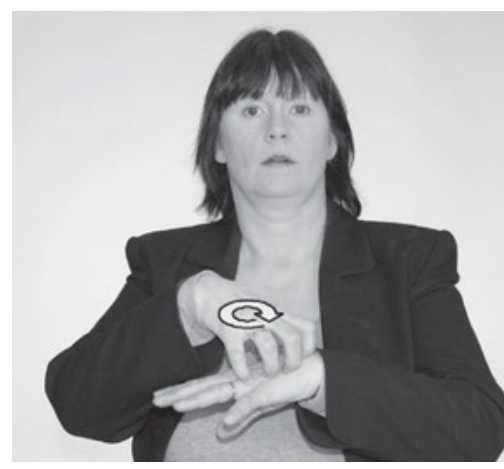

Figure 39. GREY in ÍTM (old/new sign)

The sign in figure 38 is used by old signers. It appears in the first two ÍTM dictionaries (ÍTM 1976, 1987) but not in the latest dictionary (ÍTM 2012). This sign is different from all the signs for grey in all the other Nordic sign languages. 
The sign in figure 39 does not appear in any of the ÍTM dictionaries but in the interviews our informants mentioned this sign when asked to sign the old colour signs and in the list task some informants used this sign. It is not commonly used in ÍTM today. It is identical to one of the two DTS signs for grey in the 1979 dictionary (DTS 1979) and one of the two signs for grey in STS. It is similar to the sign for grey in $\mathrm{SVK}^{34}$ and the sign for grey in the standardisation handbook (STS 2013, SVK 2013, DTS 1967). ${ }^{35}$

The sign in figure 40 is the most commonly used sign for grey in ÍTM today. It first appears in the latest dictionary (ÍTM 2012) but it is considered much older than that. This sign is similar to the other sign of the two for grey in DTS and STS (DTS 2008, STS 2013), see figures 41 and 42, but different from the signs for grey in SVK and NTS (SVK 2013, NTS 2011).

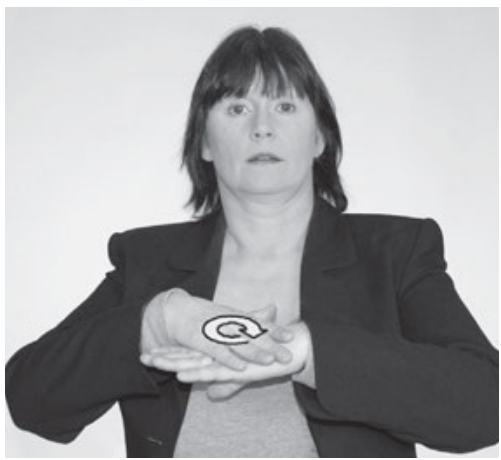

Figure 40. GREY in ÍTM (new sign) $)^{33}$

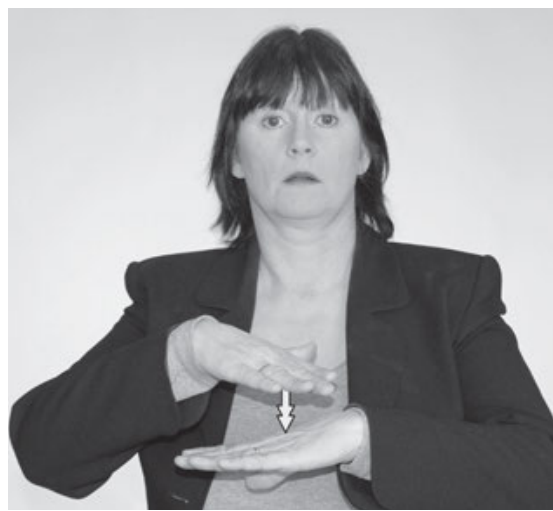

Figure 41. GREY in DTS

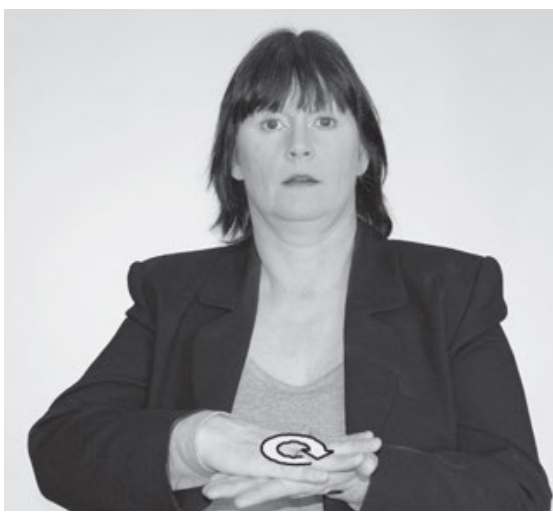

Figure 42. GREY in STS

Even though there is no data to confirm it, the lack of it tells us that the ÍTM sign in figure 39 is clearly a borrowing, either from DTS or STS. The 
movement, in case of DTS, and the orientation, in case of STS, is different from the ÍTM sign in figure 40. That sign is obviously influenced by either or both languages but not a clear example of borrowing. A sign for grey could have been made during the standardisation and then changed phonologically in each language.

\subsection{Modifications of colour terms}

The results of the colour naming task, the list task and the interviews show that modifications of colour terms in ÍTM are articulated with additional signs and non-manuals or only non-manuals.

To describe brighter, stronger, paler, lighter or darker colours the adjectives BRIGHT, STRONG, PALE, LIGHT or DARK, according to the data, appear either before or after the basic colour term, depending on signers, independent of their age and gender. Some signers also add the sign A-LITTLE before one of these adjectives if the difference in shade of colour is slight e.g. A-LITTLE DARK BLUE. In some cases informants use two additional adjectives to describe the colour, e.g. STRONG BRIGHT BLUE, PALE BRIGHT BLUE, BRIGHT LIGHT GREEN and PALE LIGHT YELLOW. The order within the AP is unclear in the data but when informants use two of the adjectives mentioned above they both appear before the basic colour term. In cases where STRONG appears with BRIGHT it seems to emphasise the brightness of the colour. In other cases, informants use the signs BRIGHT and STRONG to describe the same modification of a colour. Informants also use the same adjective for different purposes, e.g. PALE and LIGHT can be used for the purpose of describing a pale or light colour that is neither strong nor bright but they can also be used to describe a pale or light colour that is either strong or bright.

When articulating the colour term or the additional adjective, the movement can be modified. With the signs BRIGHT, STRONG and DARK the movement is speeded the brighter, stronger or darker the colour is. With the signs LIGHT and PALE the movement is slowed down.

When a colour is compared with another colour the basic colour referred to is articulated before the colour it is being compared with, e.g. GREEN BLUE refers to a colour that is 'bluish green' but BLUE GREEN refers to a colour that is 'greenish blue.' ${ }^{36}$

According to the data, four basic colour terms can be modified by a preceding noun to compare a colour with the colour of a specific object. These are modifications of the colour terms red, green, blue and pink. The 
colour 'red like wine' is signed either with the sign WINE before or after the basic colour term. The colour 'green like moss' is signed by finger spelling the Icelandic word mosi (moss) and then signing the basic colour term GREEN. The colour 'blue like the sea' is signed by articulating the sign SEA before the basic colour term. Only a small group of signers describe a specific kind of the colour pink by comparing it to the female genitalia. As in M-O-S-S GREEN and SEA BLUE the noun also precedes the colour term. Like with basic colour terms the adjectives BRIGHT, STRONG, PALE, LIGHT and DARK can either appear before or after the colour term, e.g. LIGHT M-O-S-S GREEN or RED WINE PALE.

The citation forms of the basic colour terms have neutral non-manuals. According to the data, when a basic colour term is modified, informants add non-manuals that describe the degree of the modification. The brighter or stronger the colour is, the more informants will widen their eyes, ${ }^{37}$ the lighter or paler the colour is the more informants squint their eyes and the darker the colour is the more informants frown. According to the data, the non-manuals can be added to the basic colour terms but if an additional adjective is used the non-manuals usually only accompany that.

\subsection{Summary}

In section 2 we discussed the methodology used in this study on colour terms in ÍTM. We described all basic colour terms that have signs in ÍTM and compared them with their equivalents in the other Nordic sign languages. Each subsection ended with a discussion on the signs etymology.We also discussed the modifications of colour terms according to our data. The etymology will be discussed further in section 3. Section 3 will start with a clarification of what colour terms in ÍTM meet Berlin and Kay's criteria and a discussion on the models applicability to ÍTM.

\section{Discussion}

\subsection{Basic colour terms in ÍTM}

As discussed in section 1.1 Berlin and Kay (1969) claim that any given language has eleven or fewer basic colour terms that follow an implicational hierarchy. As we have shown in section 2.2 ÍTM has signs for all these eleven colour terms, in most cases both old and new signs. According to the 
colour naming task and interviews with Deaf informants (see section 2.1 on methodology) all the signs for the eleven colour terms, both the old and the new, meet the first three criteria of Berlin and Kay's model. All the signs are monolexemic, their signification is not included in that of any other colour term and the colour terms are not restricted to a narrow class of objects.

The saliency of the colour terms was tested with the list task. Sixteen informants named altogether 291 colours, 222 of them were monolexemic signs. All informants named the same colour more than once and some named a variant of the same colour (see section 2.3 for modifications of colour terms). Indices of psychological salience include among others, according to Berlin and Kay (1969:6), "a tendency to occur at the beginning of elicitated lists of colour terms." All the monolexemic colour terms, except for grey and brown, appear as one of the first three colour terms named by the informants. The colour term red is most often named first in the list task and it is also the most frequent of first three colour terms named by informants, see table 1:

Table 1. The first three colour terms informants named in the list task

\begin{tabular}{lcccc}
\hline & $\mathbf{1}^{\text {st }}$ & $\mathbf{2}^{\text {nd }}$ & $\mathbf{3}^{\text {rd }}$ & First three colour terms, total \\
\hline Red & 8 & 3 & 5 & 16 \\
Blue & 3 & 5 & 1 & 9 \\
Black & 2 & 3 & 1 & 6 \\
White & 2 & 3 & 1 & 6 \\
Yellow & 1 & 2 & 1 & 4 \\
Green & 0 & 0 & 3 & 3 \\
Purple & 0 & 0 & 2 & 2 \\
Orange & 0 & 0 & 1 & 1 \\
Pink & 0 & 0 & 1 & 1 \\
Brown & 0 & 0 & 0 & 0 \\
Grey & 0 & 0 & 0 & 0 \\
\hline
\end{tabular}

The colour terms black, yellow and blue were named by all the sixteen informants, white, red, green, brown, purple and grey were named by all except one informant (different informant in each case), pink was named by twelve informants and orange by eleven.

Even though brown and grey were not the first three colour terms named by informants they are nevertheless named by fifteen informants, like the colour term red, which had the tendency to occur at the beginning of the list. 
Therefore brown and grey are salient for informants along with the other nine colour terms. According to the first four criteria of Berlin and Kay's model (1969) there are eleven basic colour terms in ÍTM.

According to Nyst (2007:92) only arbitrary signs should be considered basic colour terms and she claims that arbitrary colour signs are rare in sign languages. Four of the eleven (basic) colour terms, white, green, orange and grey, have arbitrary signs and should according to Nyst's claims, be the only basic colour terms in ÍTM. ${ }^{38}$ All other colour signs in ÍTM are derived and should therefore be excluded by the subsidiary criteria. ${ }^{39}$ Nyst also claims that arbitrary colour signs tend to refer to colours low in the hierarchy. The colour terms white, green, orange and grey appear in different stages in the hierarchy. Nyst's claims do therefore not hold for ÍTM.

Following Hollmann and Sutrop (2010) we argue that only in situations when the status of a term is not clear after analyzing it with the help of the four primary criteria, the subsidiary criteria should be applied.

\subsection{Influence from Danish Sign Language}

ÍTM is an autonomous language, separate from DTS. Nevertheless it has clearly been influenced by DTS as the present study reveals (see also Aldersson and McEntee-Atalianis 2008). There is a clear influence on colour signs from the Nordic sign languages, in particular DTS, at least for the newer colour signs in ÍTM.

Several factors in the history of ÍTM may have had an influence on language contact. The standardisation of the Nordic sign languages is obviously a factor, but the reason for DTS being our main focus in the comparison of ÍTM colour signs to their equivalents in other sign languages is the language contact between the two languages since mid-nineteenth century. Before 1867 deaf Icelanders were sent to school in Denmark, among them Pálsson who was the first teacher of the deaf in Iceland. None of the students that were sent to Denmark later became students at the first school in Iceland and are therefore unlikely to have had an influence on the language spoken in the school. On the other hand Pálsson can easily have brought some signs from DTS when he returned from Denmark and they then influenced the language emerging at the school, presumably the predecessor of ÍTM.

In their overview of the transmission of the Nordic sign languages, Bergman and Engberg-Pedersen (2010) imply that a possible genetic relation is between DTS and the sign languages spoken in Iceland, Greenland and the Faroe Islands due to the fact that children from all those countries 
were sent to school in Denmark in the nineteenth and twentieth century. DTS is also said to have had an influence on NTS. The history of the first years of Deaf education in Norway is practically identical to the first years of Deaf education in Iceland. The first teacher of deaf children and the founder of the first school for the deaf in Norway, Andreas Christian Møller, studied in Denmark. In Schröder's (1993) overview of the history of Norwegian Sign Language he assumes that the origin of Norwegian Sign Language is of three sources; from the manual communication between Deaf Norwegians before the establishment of the school, from Danish Sign Language through Møller and from Swedish Sign language through a Swedish Deaf teacher at the school. Bergman and Engberg-Pedersen (2010:94) conclude that the relationship between DTS and NTS is one of borrowing rather than a genetic relation.

Aldersson and McEntee-Atalianis' (2008) study shows that DTS has had an influence on ÍTM's lexicon. The historical facts about Deaf education in Iceland and its similarity to the history of Norwegian Sign Language support that the relationship between ÍTM and DTS is one of borrowing, like with DTS and NTS. The present study also reveals a clear influence from DTS on ÍTM colour signs, but since the influence is only apparent in the new signs, it is clearly an influence in terms of borrowing and not a genetic relation.

In this study we compared entries in various dictionaries to be able to estimate when influence from the other Nordic sign languages appears in ÍTM. The study reveals that the old signs in ÍTM are unlikely to have been borrowed from DTS. Nevertheless we cannot leave out the fact that due to language contact in the early and mid-nineteenth century, the language used in the first school for the deaf in Iceland may have been influenced by DTS. Therefore the significant intelligibility between the old sign for brown and the signs BLACK and RED (that have never changed) in ÍTM and their equivalents in DTS can, in theory, be traced back to DTS. Nothing in the history of ÍTM and its contact with the other sign languages leads to any influence from the other Nordic sign languages on the old ÍTM colour signs. Nevertheless all these signs are intelligible to their equivalents in the other Nordic sign languages, as well as other sign languages. Our conclusion is that this is an artefact of iconicity and the signs could easily have originated in each language independent of the other. For the newer signs, things are a bit more complicated.

There are eight basic colour terms that have new signs in ÍTM and two of them have a third sign where their time of origin is unclear (later called "middle aged" signs). All those signs are either identical or similar to various DTS colour signs found in the DTS dictionaries. In some of the 
DTS dictionaries there is more than one colour sign for some colour terms. In the charts in 1) and 2), in cases where there is more than one sign for the same colour term, we only include the sign that has the most resemblance to the ÍTM signs. The chart in 1) shows the resemblance between all the colour signs in ÍTM and DTS except for ORANGE, PURPLE and PINK since signs for purple and orange first appear in the 1967 DTS dictionary and a sign for pink first appears in the 1979 DTS dictionary (DTS 1967, 1979).

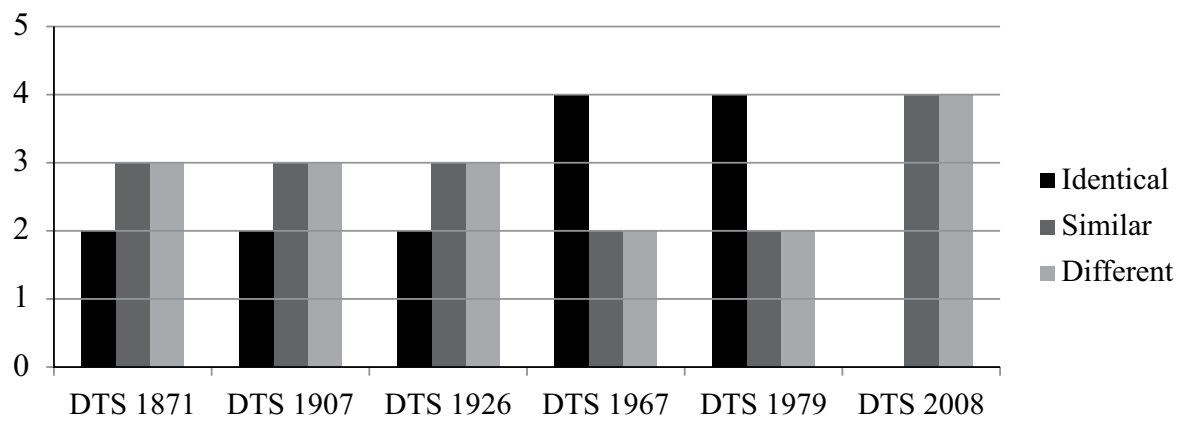

Chart 1. Eight colour signs in DTS dictionaries compared with new and middle aged signs in ÍTM.

What the chart in 1) shows is that the new and middle aged signs in ÍTM resemble the DTS signs more in the nineteenth and twentieth century than today. The standardisation period seems to have had the most impact on the borrowing of colour signs in ÍTM. The DTS colour signs seem to have changed after the 1979 DTS dictionary was published (DTS 1979) and today none of the eight ÍTM colour signs in question are identical to their equivalents in contemporary DTS.

In the chart in 2) the colour terms orange, purple and pink have been added. This chart shows an even more resemblance between ÍTM and DTS colour signs in the standardisation period that continues on to the twentieth century.

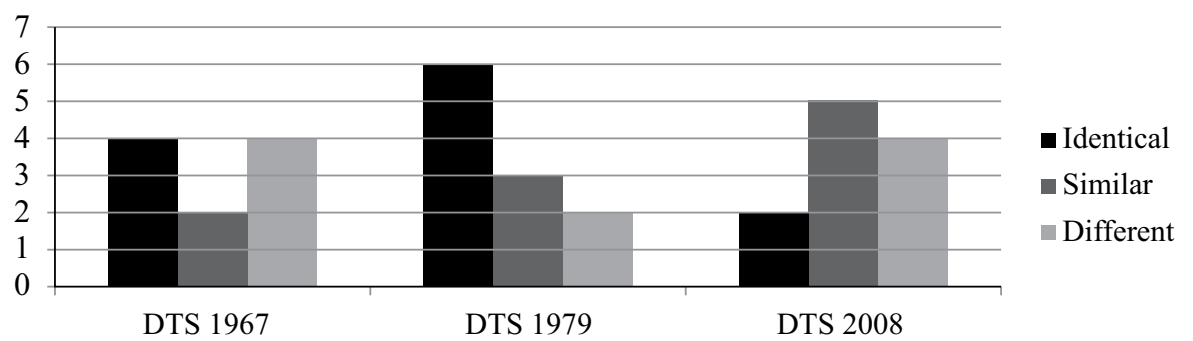

Chart 2. Eleven colour signs in DTS dictionaries compared with new and middle aged signs in ÍTM ${ }^{40}$ 
Some of the colour signs that are identical or similar to the DTS signs are also identical or similar to colour signs in NTS, STS and SVK. Since ÍTM had old signs for all these colour terms before the standardisation we cannot conclude that the new ÍTM colour signs are solely influenced by DTS but they can also be neologisms made by the DNR or influence from the other Nordic sign languages, during the standardisation.

The new signs WHITE, PURPLE, PINK and GREY and the middle aged sign for orange are clear examples of borrowing, either from DTS for the purpose of the second ÍTM dictionary (ÍTM 1987) or from the other Nordic sign languages during the standardisation. The middle aged sign for grey does not appear in any of the ÍTM dictionaries and is therefore not a clear example of a borrowing from DTS for the purpose of the second ÍTM dictionary (ÍTM 1987). It might nevertheless be a borrowing from DTS, or possibly STS, during other language contact situations. As for the new signs GREEN, BROWN and BLUE the question still remains as to whether they were borrowed from DTS for the purpose of the second ÍTM dictionary (ÍTM 1987), if they are a result of the standardisation or if their origin lies in other ÍTM signs due to their iconicity. Whether the signs RED and BLACK are borrowed or not is unclear, but their semantic relation to the real-world is the same as in many other sign languages. The sign YELLOW and the new sign ORANGE are iconic and are clearly originated in ÍTM.

\section{Conclusion}

Icelandic Sign Language has eleven basic colour terms that fit Berlin and Kay's (1969) model. The fact that they are not all arbitrary signs does not change the fact that they are basic as they all meet Berlin and Kay's primary criteria.

A language contact between ÍTM and DTS over the last centuries is likely to be a strong factor in the process of borrowing or at least for the permanence of the borrowed signs in ÍTM but iconicity also has to be taken into account.

ÍTM has both old and new signs for eight of the eleven of these colour terms. The present study reveals that the eight new signs and the two middle aged signs are either borrowed from DTS for the purpose of the second ÍTM dictionary (ÍTM 1987), the result of the standardisation lead by the DNR or they are originated in other ÍTM signs due to their iconicity.

The new sign for orange is originated in ÍTM but the middle aged sign is a clear example of a borrowing from DTS. The new signs for white, purple, 
pink and grey are also clear examples of borrowing, either from DTS or as a result of the standardisation. In the case of BROWN, GREEN and BLUE, iconicity is just as likely an explanation for the resemblance between the colour signs in the Nordic sign languages - because even in Iceland coffee is brown, the grass is green and the sky is blue!

\section{Notes}

1. The names are mentioned in alphabetical order. Rannveig Sverrisdóttir is a lecturer in Sign Language Linguistics at the University of Iceland and Kristín Lena Thorvaldsdóttir is a sign language researcher at the Communication Centre for the Deaf and Hard of Hearing in Iceland.

2. We would like to thank a number of people for their cooperation and contribution to this chapter. We would like to thank Dr. Roland Pfau, Assistant Professor at the Dept. of General Linguistics at the University of Amsterdam for his thorough review and advice, Elísa Guðrún Brynjólfsdóttir, Dr. Sigurlína Davíðsdóttir, Jette Kristoffersen, Asger Bergmann, Britta Hansen, Dr. Elisabeth Engberg-Pedersen, Dr. Päivi Rainò, Júlía Guðný Hreinsdóttir and Russell Aldersson for their comments and advice, Tómas Ásgeir Evertsson and Uldis Ozols for picture processing, Svava Jóhannesdóttir for being the face of ÍTM colour signs, and Dr. Ulrike Zeshan and Keiko Sagara for their cooperation. Last but not least we owe a debt of gratitude to all of our informants for their contribution to this chapter.

3. In this chapter we use the acronyms STS and SVK even though they are not commonly used.

4. Personal communication with Britta Hansen, former director of the Communication Center for the Deaf in Denmark (KC) and Asger Bergmann, former president of the Danish Deaf Association.

5. Here we talk about different lexical signs of the same colour term. We leave out the fact that some of them could be phonological variants of the same sign.

6. The first two ÍTM dictionaries (ÍTM 1976, 1987) were published by the Deaf Association in Iceland and the latest dictionary (ÍTM 2012) is an online dictionary hosted by the Communication Centre for the Deaf and Hard of Hearing. Both hearing and Deaf people have worked on all the dictionaries. Little or no information is available on the editing of the oldest DTS dictionaries and whether the Deaf community actually used the signs in the dictionaries. Our informants in Denmark claim that the DTS dictionary from 1979 (DTS 1979) mainly includes signs that were generally used in DTS at that time and the online DTS dictionary from 2008 (DTS 2008) only contains signs in general usage in DTS today (personal communication with Britta Hansen, 
former director of the Communication Center for the Deaf in Denmark (KC), Dr. Elisabeth Engberg-Pedersen, professor at the University of Copenhagen and Jette Kristoffersen, the main editor of the online DTS dictionary (DTS 2008).

7. The Norwegian dictionary project was led by the Møller-Trøndelag Competencecenter (NTS 2011) and the Swedish dictionary is hosted at the Sign Language Department at the University of Stockholm (STS 2013). The Finnish dictionary is based on an older book (Basic Dictionary of FinSL) published by the Finnish Deaf Association and Institute for the Languages in Finland (personal communication with Päivi Rainò, University of Applied Sciences HUMAK Helsinki). Both hearing and Deaf people have worked on all the dictionaries.

8. A one-handed and a two-handed sign that have all the same parameters are considered identical.

9. With the exception of one sign for orange and one for grey.

10. With one exception, the old sign for brown.

11. An ÍTM signer articulated the signs from the other Nordic sign language dictionaries for the purpose of this chapter.

12. The movement is repeated in the SVK sign (SVK 2013).

13. There are two other signs for white in NTS (NTS 2011).

14. Aldersson and McEntee-Atalianis (2008:68) conclude that the signs for black in contemporary ÍTM and DTS are different. That is in accordance with the signs found in the latest dictionaries (DTS 2008, ÍTM 2012).

15. Personal communication with Jette Kristoffersen, main editor of the Danish Sign Language Dictionary (DTS 2008).

16. This semantic relation can also be found in other sign languages, according to an online dictionary for German Sign Language (DGS, Deutsche Gebärdensprache) the DGS sign for NIGHT and BLACK are also identical to their equivalents in ÍTM (http://www.sign-lang.uni-hamburg.de/alex/ lemmata/s_lemma/schwarz.htm).

17. That is in accordance with Aldersson and McEntee-Atalianis' (2008:63) comparison of contemporary ÍTM and DTS.

18. Personal communication with Jette Kristoffersen, the main editor of the online DTS dictionary (DTS 2008).

19. Aldersson and McEntee-Atalianis (2008:68) conclude that the signs for green in contemporary ÍTM and DTS are different. That is in accordance with the signs found in the latest dictionaries (DTS 2008, ÍTM 2012).

20. According to Aldersson and McEntee-Atalianis (2008) a one-handed and a two-handed sign that have all the same parameters are considered identical. We argue that the place of articulation is different in the new ÍTM sign and the DTS sign in 18b. The ÍTM signs place of articulation is the non-dominant hand but the DTS signs place of articulation is neutral space. 
21. Some signers, mainly male signers, articulate this sign with a different handshape on the dominant hand.

22. Aldersson and McEntee-Atalianis (2008:68) conclude that the signs for yellow in contemporary ÍTM and DTS are different. That is in accordance with the signs found in all the dictionaries (DTS 1871, 1907, 1926, 1979, 2008, ÍTM 2012).

23. Personal communication with Jette Kristoffersen, the main editor of the online DTS dictionary (DTS 2008).

24. Some signers articulate this sign with a different handshape.

25. Some signers articulated these signs as two-handed signs.

26. According to Aldersson and McEntee-Atalianis (2008:60-61) the signs for blue in contemporary ÍTM and DTS are identical. That is not in accordance with the signs found in the latest dictionaries (DTS 2008, ÍTM 2012). Also, personal communication with Jette Kristoffersen, the main editor of the online DTS dictionary (DTS 2008).

27. Today the sign in 31a is a modification of the sign RED.

28. The mouth movement is the only difference between RED and this old sign for pink.

29. There are two signs for pink in NTS and the other one is different from the ÍTM sign.

30. The sign PINK first appears in the 1979 dictionary.

31. A sign that is similar to the ÍTM sign in 35 first appears in the 1926 DTS dictionary, under the entry appelsin which means the 'fruit orange' (DTS 1926). An entry for the colour orange first appears in the standardisation handbook (DTS 1967) saying that the colour term is a compound of the signs for red and yellow but an entry for a monolexemic sign for the colour orange first appears in the DTS dictionary from 1979 (DTS 1979). That sign is the same sign as the sign for the fruit, see figure 37.

32. Some signers us a different handshape on the dominant hand and some articulate the sign on the upper arm.

33. Some signers use a different handshape on the dominant hand.

34. The movement differs.

35. There is an inconsistency between the figure and the text below the figure in the standardisation handbook (DTS 1967), the sign could therefore also be considered identical to the ÍTM sign in figure 39.

36. According to the data, only three signers use the signs TURQUOISE BLUE to refer to a bluish green or a greenish blue colour. TURQUOISE never appears without the colour term BLUE and is therefore not monolexemic. It does not meet all of the four primary criteria of Berlin and Kay's (1969) model. It is therefore not a basic colour term in ÍTM (see further discussion on the basic colour terms in ÍTM in section 3.1). 
37. Also, signers can squint their eyes when a colour is extremely bright.

38. These are the new sign for white, the old sign for green, one of the signs for orange and all the signs for grey.

39. There are no non-native colour signs in ÍTM.

40. The sign PINK in DTS first appears in the 1979 DTS dictionary (DTS 1979).

\section{References}

Aldersson, Russell R., and Lisa J. McEntee-Atalianis. 2008. A lexical comparison of signs Icelandic and Danish Sign Languages. Sign Language Studies 9 (1):4587.

Benidiktsson, Jón K., and Árni Gíslason. 1869. Alpingistíðindi. [Report from Althingi]. Reykjavík: Alpingi.

Bergman, Brita, and Elisabeth Engberg-Pedersen. 2010. Transmission of sign languages in the Nordic countries. In Sign Languages, Diane Brentari (ed.), 74-94. Cambridge: Cambridge University Press.

Berlin, Brent, and Paul Kay. 1969. Basic Colour Terms: Their Universality and Evolution. Berkeley and Los Angeles: University of California Press.

Brynjólfsdóttir, Elísa Guðrún. 2012. Hvað gerðir pú við peningana sem frúin í Hamborg gaf pér? Myndun $h v$-spurninga í íslenska táknmálinu. [What did you do with the money that the madame of Hamburg gave you? Wh-questions in Icelandic Sign Language]. MA thesis in General Linguistics, University of Iceland.

Brynjólfsdóttir, Elísa Guðrún, and Kristín Lena Thorvaldsdóttir. 2014. Að tengja saman epli og appelsínur. Aðaltengingar í íslenska táknmálinu [Connecting apples and oranges. Conjunctions in Icelandic Sign Language]. Íslenskt mál og almenn málfræði 36:XX-XX.

Brynjólfsdóttir, Elísa Guðrún, Jóhannes Gísli Jónsson, Kristín Lena Thorvaldsdóttir and Rannveig Sverrisdóttir. 2012. Málfræði íslenska táknmálsins. [The grammar of Icelandic Sign Language]. Íslenskt mál og almenn málfraði 34:9-52.

Guðjónsdóttir, Hervör. 1987. Formáli [Preface]. Táknmálsorðabók [Sign Language Dictionary], 7-8. Reykjavík: Félag heyrnarlausra.

Guðmundsdóttir Beck, Thórhalla. 2013. Í landi myndanna. Um merkingu og uppruna lýsandi orða í táknmáli [In the kingdom of images. On meaning and origins of descriptive words in sign language]. MA thesis in General Linguistics, University of Iceland. 
Hollman, Liivi and Urmas Sutrop. 2010. Basic color terms in Estonian Sign Language. Sign Language Studies 11(2):130-157.

Kay, Paul, and Chad K. McDaniel. 1978. The linguistic significance of the meanings of basic color terms. Language 54 (3):610-646.

Nyst, Victoria. 2007. A Descriptive Analysis of Adamorobe Sign Language (Ghana). Utrecht: LOT.

Pálsson, Páll. 1867. Auglýsingar [Advertisements]. Pjóðólfur 19 (46):188.

Pálsson, Páll. 1874a. Heyrnar- og málleysingjaskólinn á Prestbakka [School for the deaf and mute in Prestbakki]. Vikverji 2(6):134.

Pálsson, Páll. 1874b. Heyrnar- og málleysingjaskólinn á Prestbakka, framhald [School for the deaf and mute in Prestbakki, continuation]. Vikverji 2(7):140.

Schröder, Odd-Inge. 1993. Introduction to the history of Norwegian Sign Language. In Looking Back. A Reader on the History of Deaf Communities and their Sign Languages, Renate Fischer and Harlan Lane (eds.), 231-248. Hamburg: Signum Press.

Sigurbjörnsdóttir, Kristbjörg. 2011. Um kynslóðamun í íslensku táknmáli. Rannsókn á kynslóðabundnum málfarsmun í íslensku táknmáli. [On generational variation in Icelandic Sign Language. Research on generational variation in Icelandic Sign Language]. BA thesis in Sign Language Linguistics, University of Iceland.

Sverrisdóttir, Rannveig. 2000. Signing simultaneous events. The expression of simultaneity in children's and adults' narratives in Icelandic Sign Language. Cand.mag. thesis in General linguistics, University of Copenhagen.

Thorvaldsdóttir, Guðný Björk. 2008. Mental Space Theory and Icelandic Sign Language. Institute of Technology Blanchardstown Journal 17:5-19.

Thorvaldsdóttir, Kristín Lena. 2011. Sagnir í íslenska táknmálinu. Formleg einkenni og málfræðilegar formdeildir [Verbs in Icelandic Sign Language. Formal features and grammatical categories]. MA thesis in Icelandic grammar, University of Iceland.

Thorvaldsson, Reynir Berg. 2010. Saga heyrnarlausra á Íslandi. [The History of the Deaf in Iceland.] Reykjavík: Félag heyrnarlausra.

Wierzbicka, Anna. 2008. Why are there no 'colour universals' in language and thought. Journal of the Royal Anthropological Institute 14:407-425.

Woodward, James. 1989. Basic colour term lexicalization across Sign Languages. Sign Language Studies 63:141-152. 


\section{Dictionaries}

ASL $2008=$

2008 Random House Webster's Unabridged American Sign Language Dictionary Elaine Costello (ed.). New York: Random House Reference.

BSL $2011=$

2011 Signstation. Bristol: University of Bristol. Centre for Deaf Studies. Online at http://www.signstation.org/index.php/bsl-dictionary/ desktop-dictionary.

DTS $1871=$

1871 De Dövstummes Haandalphabet samt et Udvalg af deres lettere Tegn. [The Deaf-Mute Handalphabet and a Selection of Their Simple Signs]. Copenhagen: A. C. Nyegaard.

DTS $1907=$

1907 De døvstummes Haandalfabet og 280 af de almindeligste Tegn. [The Deaf-Mute Handalphabet and 280 of the most Common Signs.] Copenhagen: Johs. Jørgensen.

DTS $1926=$

1926 Ordbog i De Døvstummes Tegnsprog. [Dictionary of the DeafMute Sign Language]. Copenhagen: Døvstumme-Raadet.

DTS $1967=$

1967 Håndbog i tegnsprog. [Handbook for Sign Language(s)]. Copenhagen: Danske Døves Landsforbund.

DTS $1979=$

1979 Dansk-tegn ordbog. [Danish-Sign Dictionary]. Ole Munk Plum, Lene Søndergaard, Dorte Artmann, Ruth Kjær Sørensen, Ole Hagedorn-Olsen, Annegrethe Pedersen (eds.). Copenhagen: Danske Døves Landsforbund.

DTS $2008=$

2008 Ordbog over Dansk Tegnsprog. [Danish Sign Language Dictionary] Jette Kristoffersen (main editor). Copenhagen: Center for Tegnsprog og Tegnstøttet Kommunikation - KC in collaboration with Danske Døves Landsforbund. Online at www. tegnsprog.dk.

ÍTM $1976=$

1976 Táknmál. [Sign Language]. Reykjavík: Félag heyrnarlausra. 
ÍTM $1987=$

1987 Táknmálsorðabók. [Sign Language Dictionary]. Reykjavík: Félag heyrnarlausra.

ÍTM $2012=$

2012 SignWiki Ísland. [SignWiki Iceland]. Árný Gudmundsdóttir (ed.). Reykjavík: Samskiptamiðstöð heyrnarlausra og heyrnarlausra. Online at www.signwiki.is

NTS $2011=$

2011 Norsk Tegnordbog. [Norwegian Sign Language Dictionary]. Trondheim: Møller-Trøndelag Kompetansesenter. Online at http:// www.tegnordbok.no/

STS $2013=$

2013 Svensk teckenspråkslexikon. [Swedish Sign Languages Lexicon]. Stockholm: Afdeling for teckenspråk, Institutionen för lingvistik, Stockholms universitet. Online at: http://130.237.171.78/fmi/iwp/ cgi?-db=Svenskt\%20teckenspr\%C3\%A5kslexikon\&-loadframes.

SVK $2013=$

2013 Suvi - Suomen viittomakielten verkkosanakirja. [On-line dictionary of Finnish Sign Language]. Helsinki: Finnish Association of the Deaf. Online at http://suvi.viittomat.net 
